\title{
Efficacy of Hummel (Modified Schlumberger) Arrays of Vertical Electrical Sounding in Groundwater Exploration: Case Study of Parts of Ibadan Metropolis, Southwestern Nigeria
}

\author{
Micheal Oladunjoye and Solomon Jekayinfa \\ Department of Geology, University of Ibadan, Oyo State, Ibadan 200285, Nigeria \\ Correspondence should be addressed to Solomon Jekayinfa; soljjc@gmail.com
}

Received 9 September 2014; Revised 4 January 2015; Accepted 5 January 2015

Academic Editor: Rudolf A. Treumann

Copyright (C) 2015 M. Oladunjoye and S. Jekayinfa. This is an open access article distributed under the Creative Commons Attribution License, which permits unrestricted use, distribution, and reproduction in any medium, provided the original work is properly cited.

\begin{abstract}
This research compared the interpretation results of the Vertical Electrical Sounding data acquired using the conventional Schlumberger and modified Schlumberger arrays with a view to assessing the effectiveness of the modified Schlumberger arrays of vertical electrical sounding as an alternative to the conventional Schlumberger array at sites with space constraint during groundwater exploration. A total of thirty-seven (37) sounding locations were occupied and one hundred (100) sounding data for both conventional Schlumberger and modified Schlumberger arrays were collected across different rock units within Ibadan metropolis, south-western Nigeria, with electrode spacing $(A B / 2)$ ranging from 1 to $75 \mathrm{~m}$. The field data were interpreted qualitatively by curve matching and computer iterative methods. Also, statistical analysis of subsurface units and the coefficient of correlation " $R$ " of the statistical plots of the field data shows the relationship between the different arrays. The raw data plot of the different arrays shows significant similarities while statistical analysis of the geo-electric parameters obtained from the different arrays across varied lithologic units show that strong relationships exist between the different field methods. The coefficient of correlation $R$ with values ranging from 0.7 to 0.99 implies that a good similarity exists between the different field methods employed in this study. Hence, modified Schlumberger arrays can be said to be a good alternative to the conventional Schlumberger array for groundwater exploration especially in urban settings where space constraint is a major challenge.
\end{abstract}

\section{Introduction}

The development of available groundwater resources is a significant aspect of the provision of potable water in urban and rural settings. For years, various geophysical techniques have been employed either singly or in combination in the search for groundwater. In recent times however, technology advancements have brought about the use of state of the art geophysical techniques in groundwater exploration in complex terrains such as the use of magnetic and DC resistivity surveys in semiarid or arid terrains [1]. Dowsing, an ancient traditional method of exploration, used jointly with the modern slingram electromagnetic survey method and vertical electrical sounding in finding groundwater, revealed more accurate results when the three methods are analysed jointly such that the vulnerability of errors linked to a single method is overcome; thus information from the three methods can be used to pinpoint prospective drilling sites for groundwater with a high degree of accuracy [2]. The use of ground penetrating radar in determining groundwater surfaces by studying the responses of the electromagnetic waves reflected from the water table has been used in recent times in prospecting for groundwater occurrences mostly in sedimentary terrains with low electrically conductive sediments [3-6] and sometimes in crystalline rock terrains [7]. Other modern geophysical techniques for groundwater exploration include the use of airborne electromagnetic inductions [8] and seismic refraction survey in conjunction with vertical electrical sounding (VES) resistivity method [9].

The most popular configuration in vertical electrical sounding (VES) is the conventional Schlumberger array, which has a symmetrical layout with electrodes spread on 
either sides of the array spread [11-17]. However, geophysical investigation especially in highly developed or congested and thickly vegetated areas proved very challenging due to the inaccessibility of sites to conduct soundings of symmetrical configuration of electrodes to the required spacing. This is often responsible for incompleteness of field data. Consequently, the asymmetrical array of electrodes in vertical electrical sounding as described by Nick and Katerina [18] as well as Akintorinwa and Abiola [19] and referred to as modified Schlumberger array (Hummel method) could be employed as an alternative to alleviate problems of space constraint. In electrical resistivity method, there are many arrays which can be used. This includes Schlumberger, modified Schlumberger, Dipole-Dipole, Wenner, and Pole-Pole, among others. Most commonly used among the arrays mentioned above for vertical electrical sounding (VES) is the Schlumberger array, which requires large spacing at both ends for deeper information. The modified arrays enable vertical electrical sounding with the movement of current electrode $\left(C_{2}\right)$ while the other current electrode $\left(C_{1}\right)$ is fixed perpendicular $\left(90^{\circ}\right)$ to the line of spread, while the potential electrode remains temporarily fixed as in the conventional Schlumberger array. This research attempts a comparative study of the conventional Schlumberger and modified Schlumberger arrays in terms of deduced geoelectric parameters, in order to determine the efficacy of the modified Schlumberger arrays for groundwater exploration in developed areas with space constraint as an alternative to the conventional Schlumberger array.

\section{Location and Physiography of the Study Area}

Ibadan lies between longitudes $3^{\circ} 45^{\prime}$ and $4^{\circ} 00^{\prime} \mathrm{E}$ and latitudes $7^{\circ} 15^{\prime}$ and $7^{\circ} 30^{\prime} \mathrm{N}$ (Figure 1(a)) within the basement complex terrain of south western Nigeria and covers about $300 \mathrm{~km}^{2}$. Olayinka and Adeyemi [20] described the scenery as being dominated by three major landforms units, namely, the hills, plains, and river valleys. The hills are the most striking features. Although they constitute less than $20 \%$ of the total surface area, two main types can be recognized, namely, quartzite ridges and gneissic inselbergs, of which the former are by the most extensive landform system in the area with an altitude generally ranging from 185 to $222 \mathrm{~m}$ above mean sea level [21]. They cover, essentially, the areas between the hill bases and the usually entrenched valley bottoms.

\section{Geology of the Study Area}

Ibadan, a region in the south-western part of Nigeria, is located within the Nigerian basement complex which lies between the West African craton which demarcates the panAfrican belt [22]. The Precambrian basement complex of Nigeria may be distinguished into three major successions, a remobilized ancient complex of gneisses and migmatites, a series of approximately N-S trending schist belt, and an intrusive suite of gneisses of pan-African (600 Ma) granites and related rocks. The complex of gneisses and migmatites include minor quartzite and calc-silicate bearing units which bear imprints of Liberian (Ca $2500 \mathrm{Ma}$ ) and Eburnean (Ca $2000 \mathrm{Ma}$ ) events [23].

Ibadan is dominated by rock types such as granite and schist of the metasedimentary scores, banded gneiss and granite gneiss, augen gneiss, and migmatite complex (Figure 1(b)). Quartzite (quartz schist) outcrops occur as ridges with relatively high elevation and are commonly schistose in form. Their strike line runs in the northsouth direction between $340^{\circ}$ and $350^{\circ}$ consistently dipping eastwards with characteristic cross-cutting features [24].

The study area is underlain by banded and augen gneisses, schistose quartzite (quartz schist), and amphibolite [25]. The study of the weathered rock and soil cover indicates that they are being derived from the weathering of the basement rock which underlain them, the rock is highly weathered and fractured with well-developed foliation planes and strikes between $34^{\circ}$ and $352^{\circ}$ and dipping between $27^{\circ}$ and $37^{\circ} \mathrm{E}$ [26].

\section{Hydrogeology of the Study Area}

Ibadan the study area is situated within the basement complex of southwestern Nigeria, consisting mainly of Precambrian crystalline rocks. Generally, the basement rocks in their unaltered form are characterized by low porosity and permeability. Therefore the occurrence of groundwater in this region depends on the existence of thick weathered and/or deep fractured zones. In Ibadan area, the weathered profile developed above crystalline basement rocks comprises, from top to bottom, the soil layer, the saprolite (product of in situ chemical weathering of the bedrock), the saprock (fractured bedrock), and the fresh bedrock [27]. The recharge of the aquifers is mainly by the annual rainfall infiltrations and discharges artificially through dug wells and boreholes [28].

\section{Methodology}

Vertical electrical sounding (VES) measures vertical variation of ground resistivity with depth in respect to a fixed station. This is carried out by gradually increasing the interelectrodes spacing at about a fixed centre of array [29]. Conventional Schlumberger array utilizes four electrodes system which are arranged linearly with different interelectrode spacing, the potential electrode remains partially fixed at the center of the spread, and the current electrode is expanded symmetrically about the centre of the spread (Figure 2) as described by Telford et al. [30] and Parasnis [31]. The geometric factor is

$$
\begin{aligned}
K_{s}= & 2 \pi\left(\frac{1}{a}-\frac{b}{2}\right)-\left(\frac{1}{a}+\frac{b}{2}\right)-\left(\frac{1}{a}+\frac{b}{2}\right) \\
& +\left(\frac{1}{a}-\frac{b}{2}\right), \\
K_{s}= & \pi\left(\frac{a^{2}}{b}-\frac{b}{4}\right) .
\end{aligned}
$$



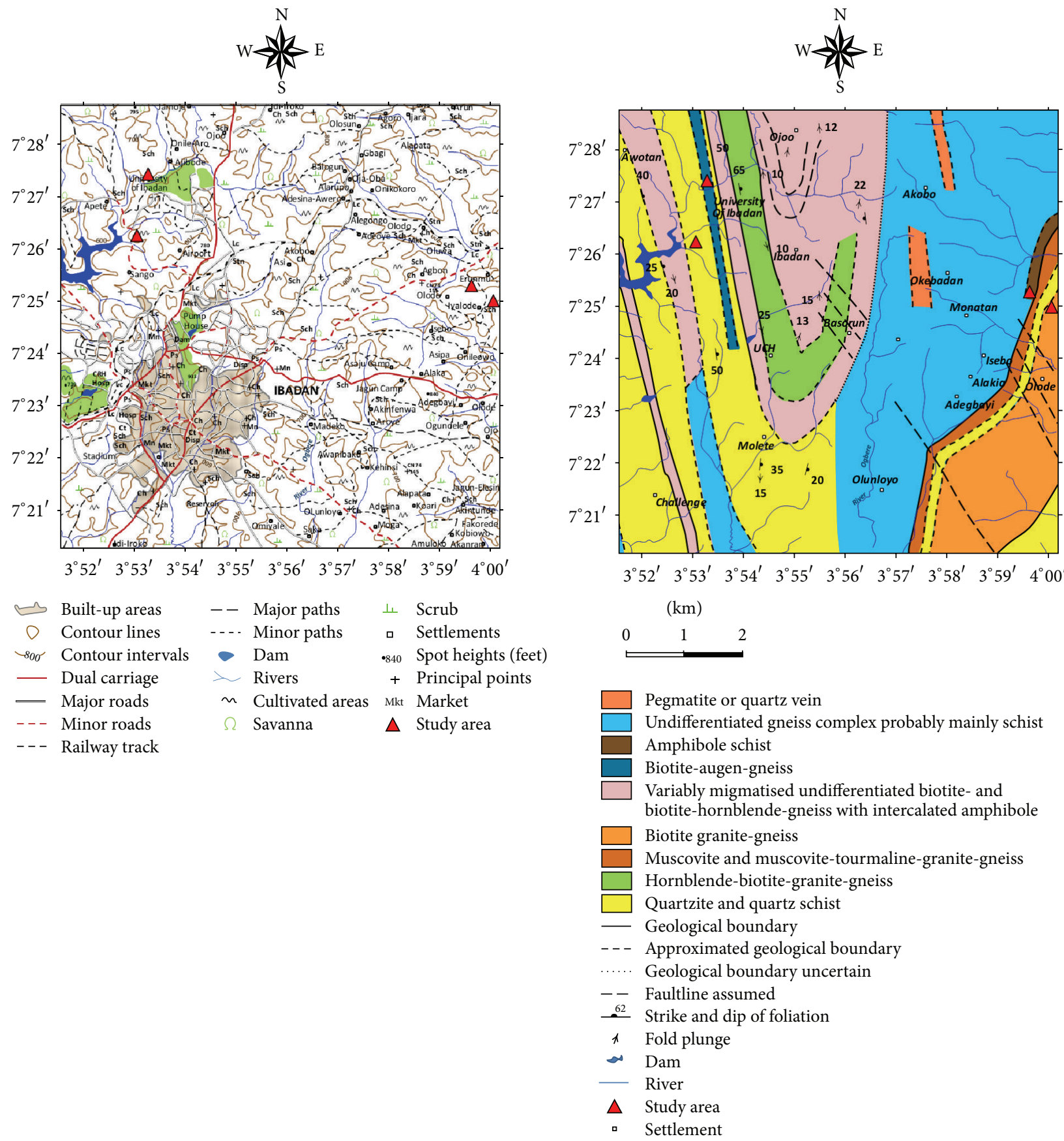

(a)

(b)

FIgURE 1: (a) Location map of Ibadan showing the study area. (b) Geological map of Ibadan [10].

With the expression, the electric field is approximately determined; thus

$$
\begin{aligned}
& K_{s}=\pi \frac{a^{2}}{b}, \\
& \rho_{a}=R \cdot K, \\
& \rho_{a}=\pi \frac{a^{2}}{b} \cdot R .
\end{aligned}
$$

In this array, the measuring electrodes are placed closely together such that the ratio of the measured voltage to the separation is approximately equal to the voltage gradient at the midpoint of the current spread. However, in the Hummel and "Half-Hummel" (modified Schlumberger) methods of vertical electrical sounding, the potential electrodes remain temporarily fixed while one of the current electrodes is kept fixed throughout the sounding operation at a distance equal to the mobile current electrode spacing " $L$ " (known as the 


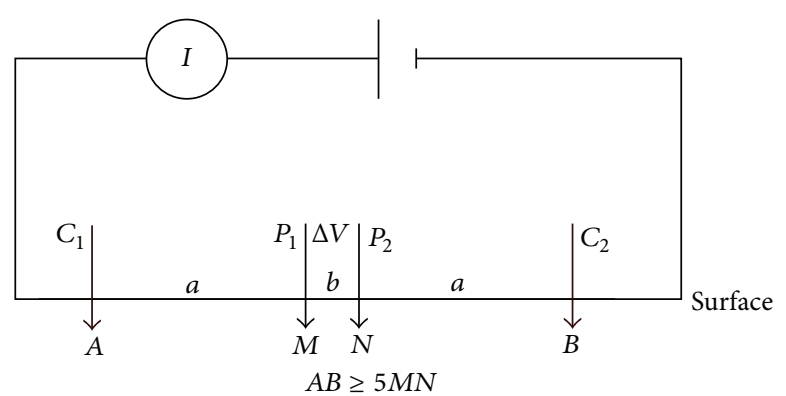

FIGURE 2: Electrode configuration for conventional Schlumberger array.

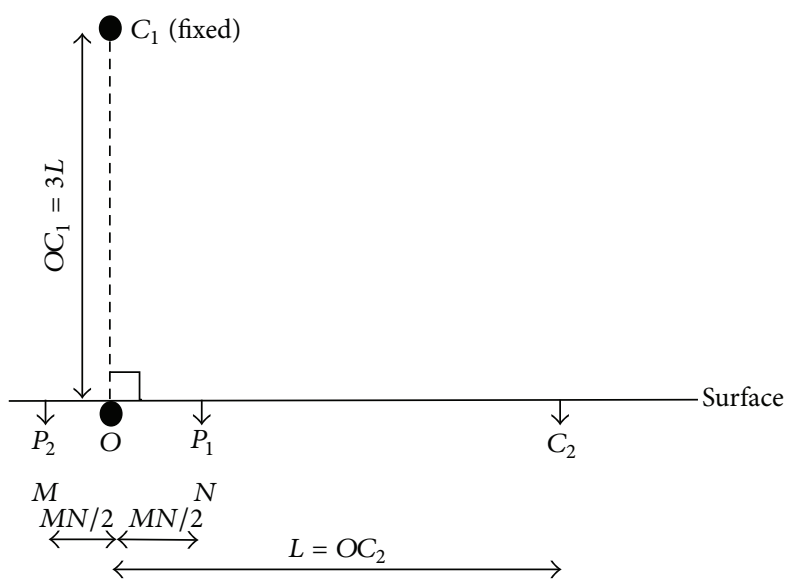

FIGURE 3: Diagrammatic representation of the electrode configuration in Hummel method (modified Schlumberger array). Note that when the distance $O C_{1}=O C_{2}=L$, we have the "Half-Hummel" method.

Half-Hummel method) or three times the mobile current electrode, that is, " $3 L$ " (Hummel array) and perpendicular to the line of electrode spread as shown in Figure 3. The geometric factor of the modified Schlumberger arrays $K_{H}$ was estimated to be twice that of the conventional Schlumberger array $K_{s}[32]$ that is

$$
\begin{aligned}
K_{H} & =2 K_{s}, \\
\rho_{a} & =R \cdot K_{H},
\end{aligned}
$$

where $K_{s}=$ geometric factor for conventional Schlumberger array, $K_{H}=$ geometric factor for Hummel and "HalfHummel" (modified Schlumberger) arrays, $\rho_{a}=$ apparent resistivity, and $R=$ resistance of subsurface layer.

This research was conducted on different geological units at different stations to ascertain the efficacy of the Hummel and "Half-Hummel" arrays. Conventional Schlumberger array was adopted in conjunction with the Hummel and "Half-Hummel" arrays with the current electrode $(A B / 2)$ spacing ranging from 1.0 to $75 \mathrm{~m}$. The fixed current electrode $\left(C_{1}\right)$ was placed at a distance three times the current electrode spacing (i.e., $3 \times A B / 2$ ) or equal to the current electrode spacing for the Hummel array and "Half-Hummel" array, respectively, and the results were compared with conventional Schlumberger array at every location of study. Figure 4 shows the application of the Hummel or "Half-Hummel" method in congested and/or developed areas where symmetrical spread of current electrodes is not feasible.

One hundred (100) vertical electrical soundings (VES) were carried out in the study area which was fairly distributed across different geological units using both the conventional Schlumberger and modified Schlumberger arrays at every station. The areas investigated include KumapayiOlodo community (banded gneiss terrain), Oki community (amphibolite terrain), University of Ibadan campus (augen gneiss and quartz schist terrain), Polytechnic Ibadan Campus (quartz schist terrain), and Ajibode community (augen gneiss terrain). The Geopulse Campus Tigre resistivity meter was used for data collection. Garmin's global positioning system (GPS) was used to record the geographic coordinates of the VES stations.

Field precautions observed during this research exercise include siting of sounding centres where potential electrodes will encounter little surface inhomogeneity, since surface inhomogeneities introduce misleading results in the potential reading by distorting the current flow pattern. Also, good contact was ensured at the current electrodes by driving the electrodes sufficiently deep into the surfaces and proper tightening of current and potential cables to their respective electrodes. Cables were checked properly to avoid current leakages during measurement for good quality data. Good conductors like wire fences, underground telephone lines, 


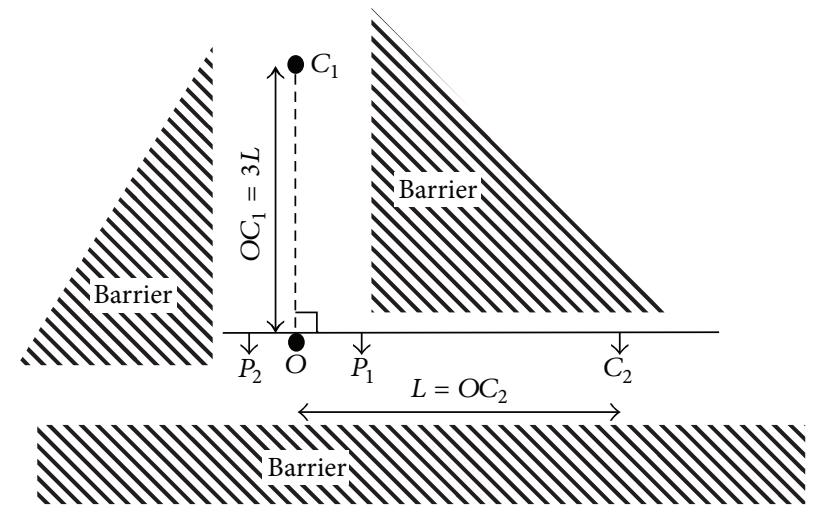

FIGURE 4: Diagrammatic representation of electrode spread in congested area with limited access illustrating Hummel array.

and pipes with tendencies to distort the current pattern were avoided by placing the potential electrodes as far as possible away from them; hence most of the readings were taken on open fields and along dirt roads where presence of these objects are minimal. Power lines, especially those accompanied by earth wires, create nuisance when measurements are taken close by as they introduce high voltages in the ground. Such were therefore avoided completely.

The apparent resistivity measurements at each VES stations for both the conventional Schlumberger and modified Schlumberger (Hummel and "Half-Hummel") arrays were plotted against electrode spacing on bilogarithmic graph sheet. The resulting curves were then inspected visually to determine the nature of the subsurface layering delineated by both arrays. Partial curve matching was carried out for the quantitative interpretation of the curves [32, 33]. The results of the curve matching (layer resistivity and thickness) were fed into the computer as starting model parameter in an iterative forward modelling technique using WINRESIST computer software. With the advent of computing facilities the inversion process has become widely used in geophysical data interpretation. Inversion is an iterative process that is controlled by a mathematical equation [34]. A model is proposed from the field data and fed into a computer and an inversion programme is run; the result of which is a new model whose parameters are compared to the field data. These parameters are altered and again run in the computer. This is repeated until a model is found whose calculated data best matches the field data. From the inversion results (layer resistivity and thickness), layer parameter charts were generated. Statistical calculation (test of significance) and the coefficient of correlation " $R$ " of the statistical-plots of the layer parameters were carried out in order to estimate the relationship between the different arrays used.

For the test of significance, both the raw data and layer parameters using the various means and variance were subjected to statistical treatment at $5 \%$ level of significance as follows.

(i) Null hypothesis $\left(U_{\mathrm{NH}}\right)$ : there is a significant relationship between the parameters.

(ii) Alternative hypothesis $\left(U_{T}\right): U_{T}$ is 1.96 at $5 \%$ level of significance from standard normal variant table. (iii) Level of significance: $5 \%$.

(iv) Criterion: accept null hypothesis if $U_{\mathrm{NH}}<U_{T}$ (significance relationship exists between parameters); reject if $U_{\mathrm{NH}}>U_{T}$ (i.e., no significance relationship exists between parameters).

The standard normal variate is

$$
U_{\mathrm{NH}}=\frac{x_{1}-x_{2}}{\sqrt{\left(\partial / n_{1}+\partial / n_{2}\right)}},
$$

where $x_{1}=$ mean of first parameter, $x_{2}=$ mean of second parameter, $\partial_{1}=$ variance of first parameter, $\partial_{2}=$ variance of second parameter, $n_{1}=$ sample size of first parameter, $n_{2}$ = sample size of second parameter, $U_{\mathrm{NH}}{ }^{1}=$ null hypothesis test for conventional Schlumberger array versus Hummel array, and $U_{\mathrm{NH}}{ }^{2}=$ null hypothesis test for conventional Schlumberger array versus "Half-Hummel" array.

\section{Results and Discussion}

6.1. Presentation of Results. The results are presented as field curves showing layer parameters, tables, histograms showing test of hypothesis results, and statistical correlation plots. The summary of the VES interpretation results for the conventional Schlumberger and modified Schlumberger (Hummel and Half-Hummel) at VES stations occupied across different geological units within the study area are presented in Table 1. Three to five layers were delineated from inverted curves generated from both arrays. The same curve types were identified by both arrays at almost all the sounding stations (Table 1).

For locations with banded gneiss lithology, the maximum number of layers observed was three. The range of weathered layer resistivity is between 15 and $66 \Omega \mathrm{m}$ (clayey), with overburden thickness ranging between 2.3 and $6.8 \mathrm{~m}$; the basement resistivity ranges between 411 and $3277 \Omega \mathrm{m}$ for the different array methods employed. For locations with amphibolite lithology, the maximum number of layers observed was four. The range of weathered layer resistivity is between 12 and $65 \Omega \mathrm{m}$ (clayey), with overburden thickness ranging between 1.7 and $29.4 \mathrm{~m}$; the basement resistivity ranges between 62 and $683 \Omega \mathrm{m}$ for the different array methods employed. Also, 


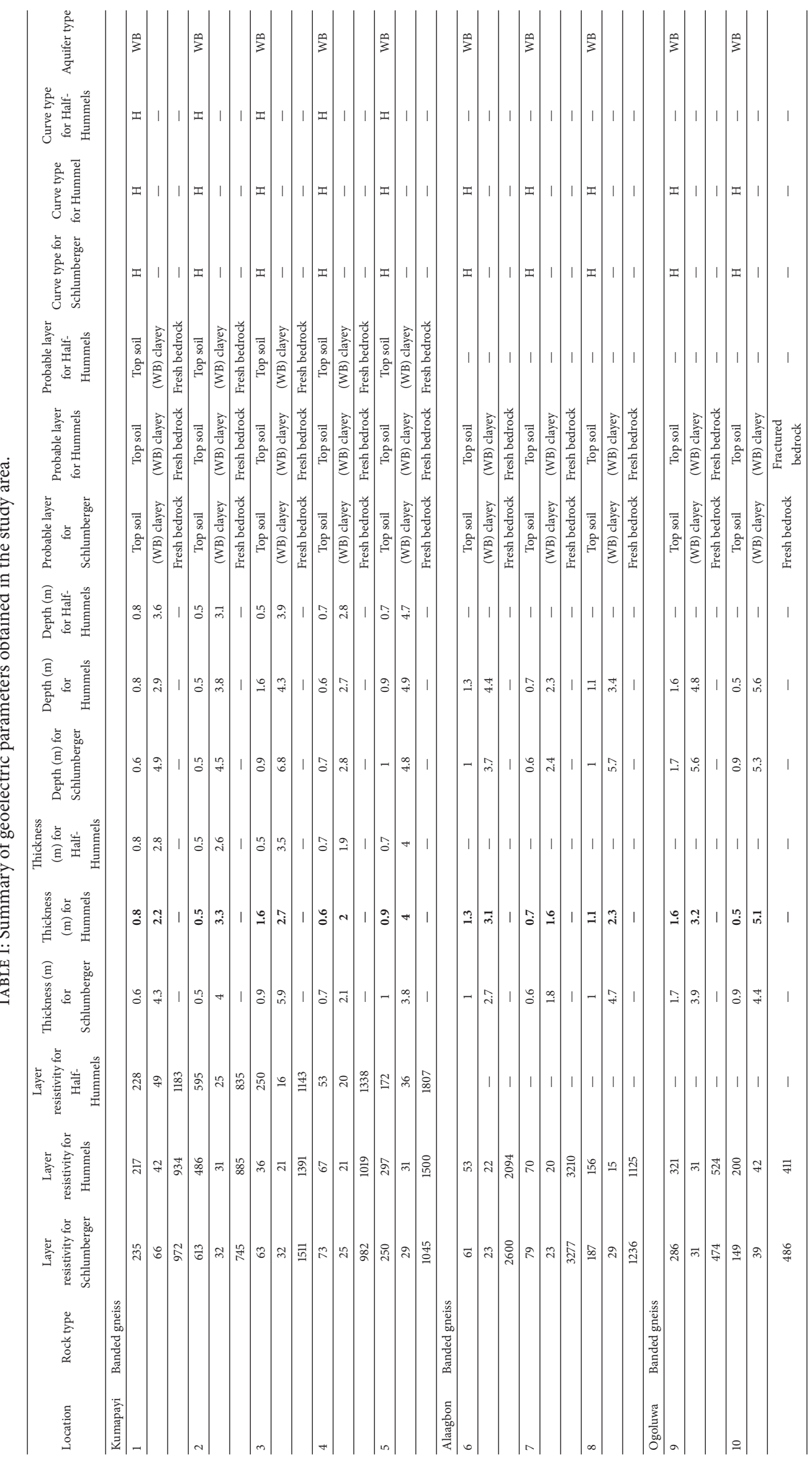




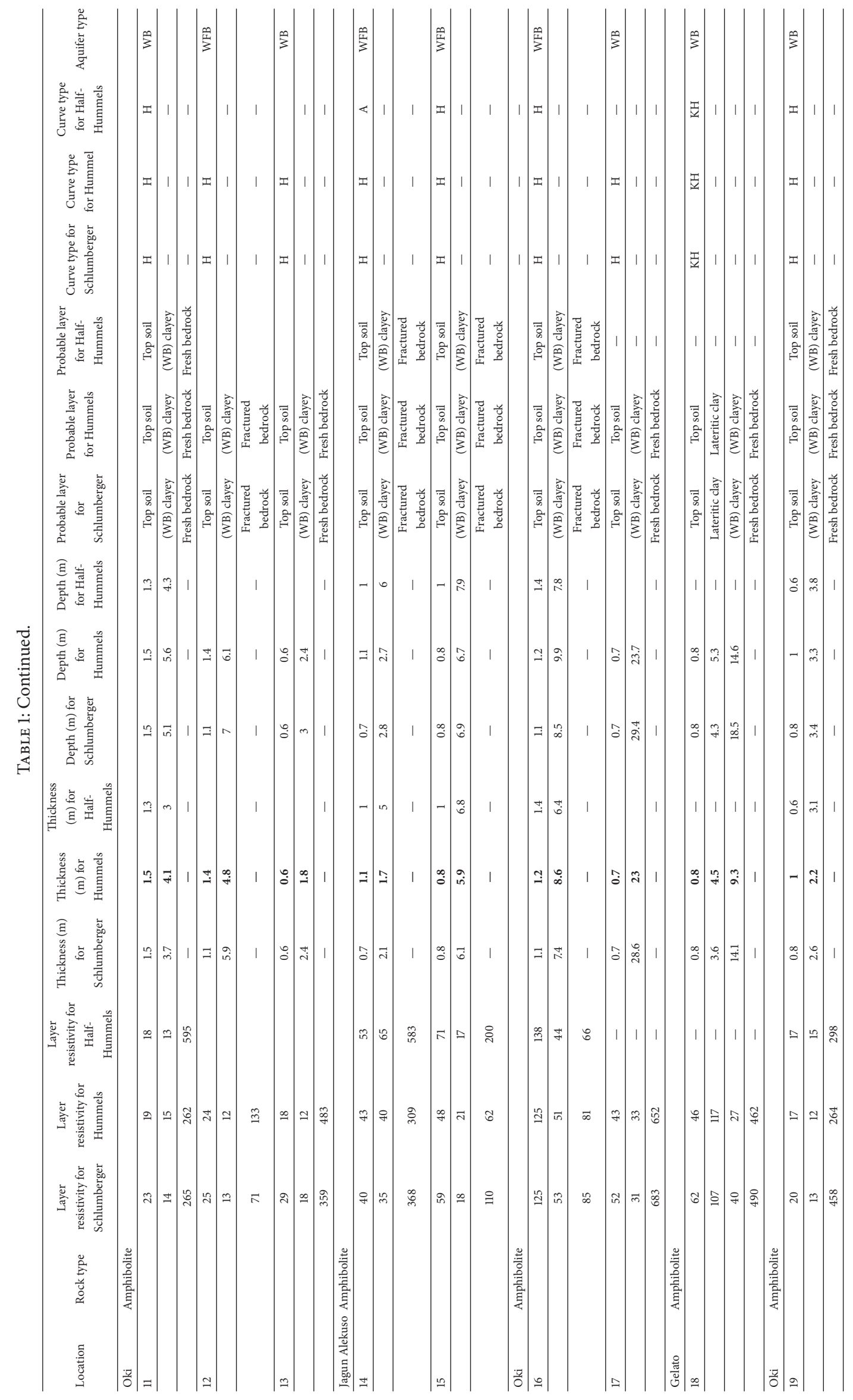




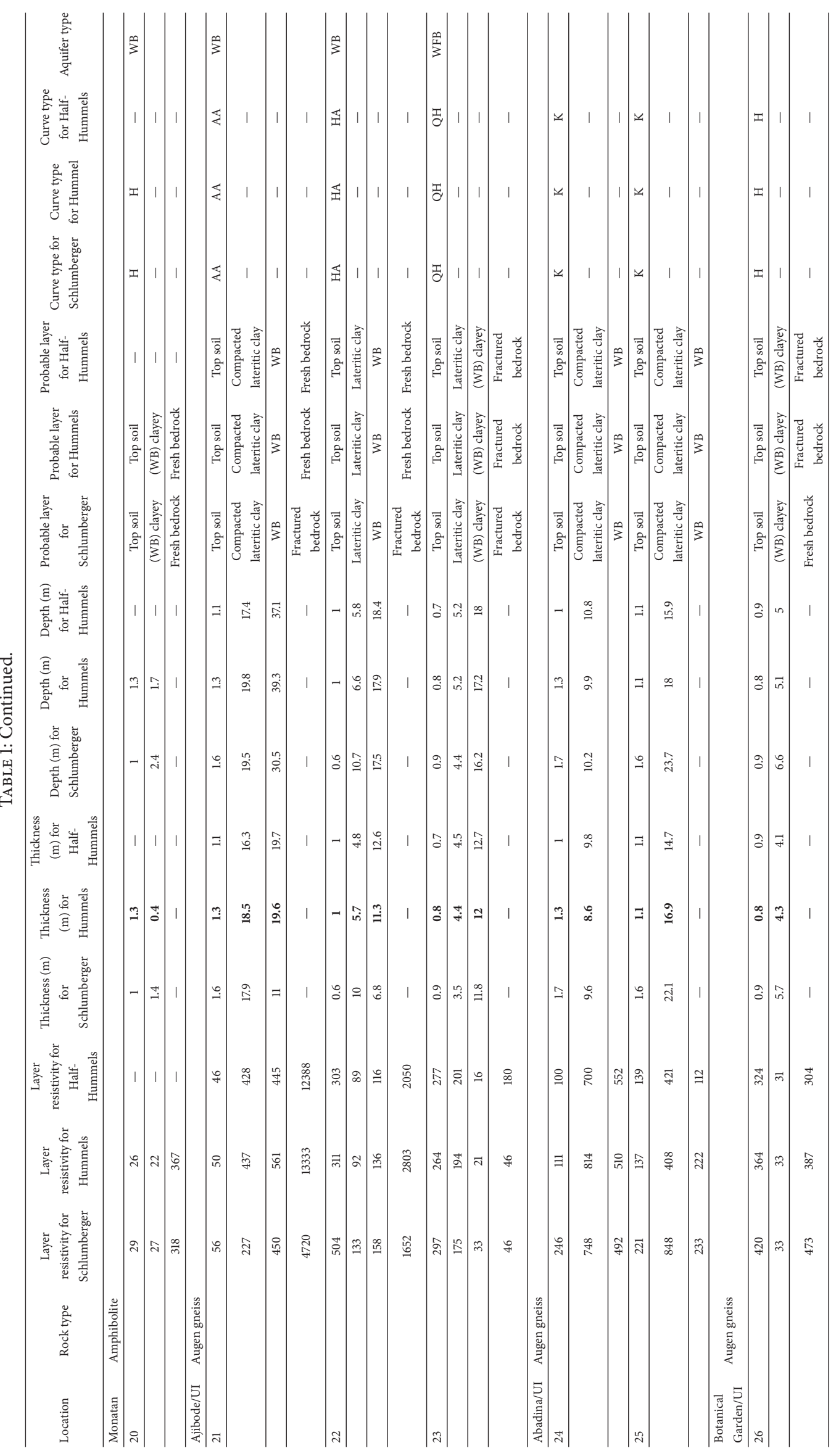




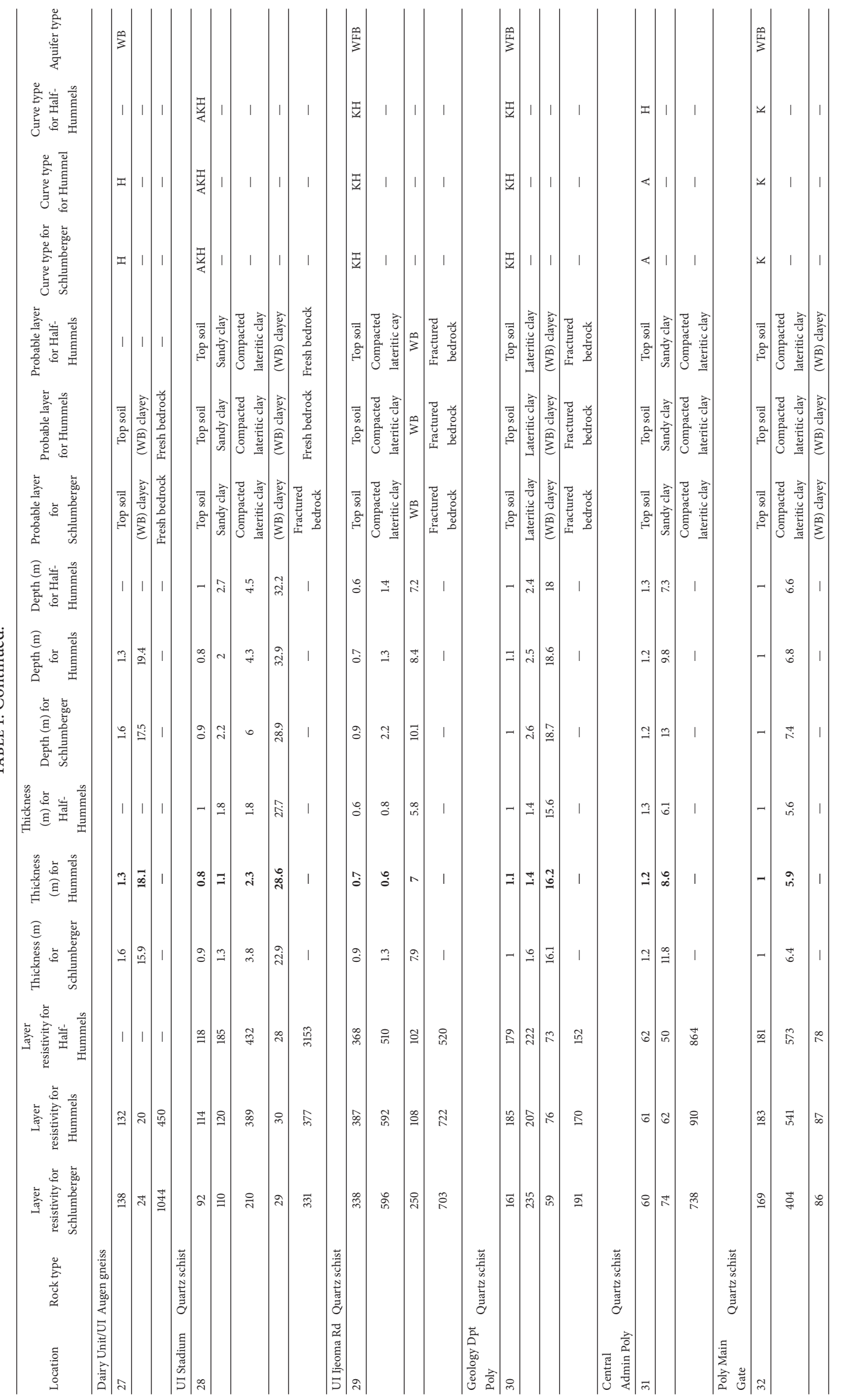




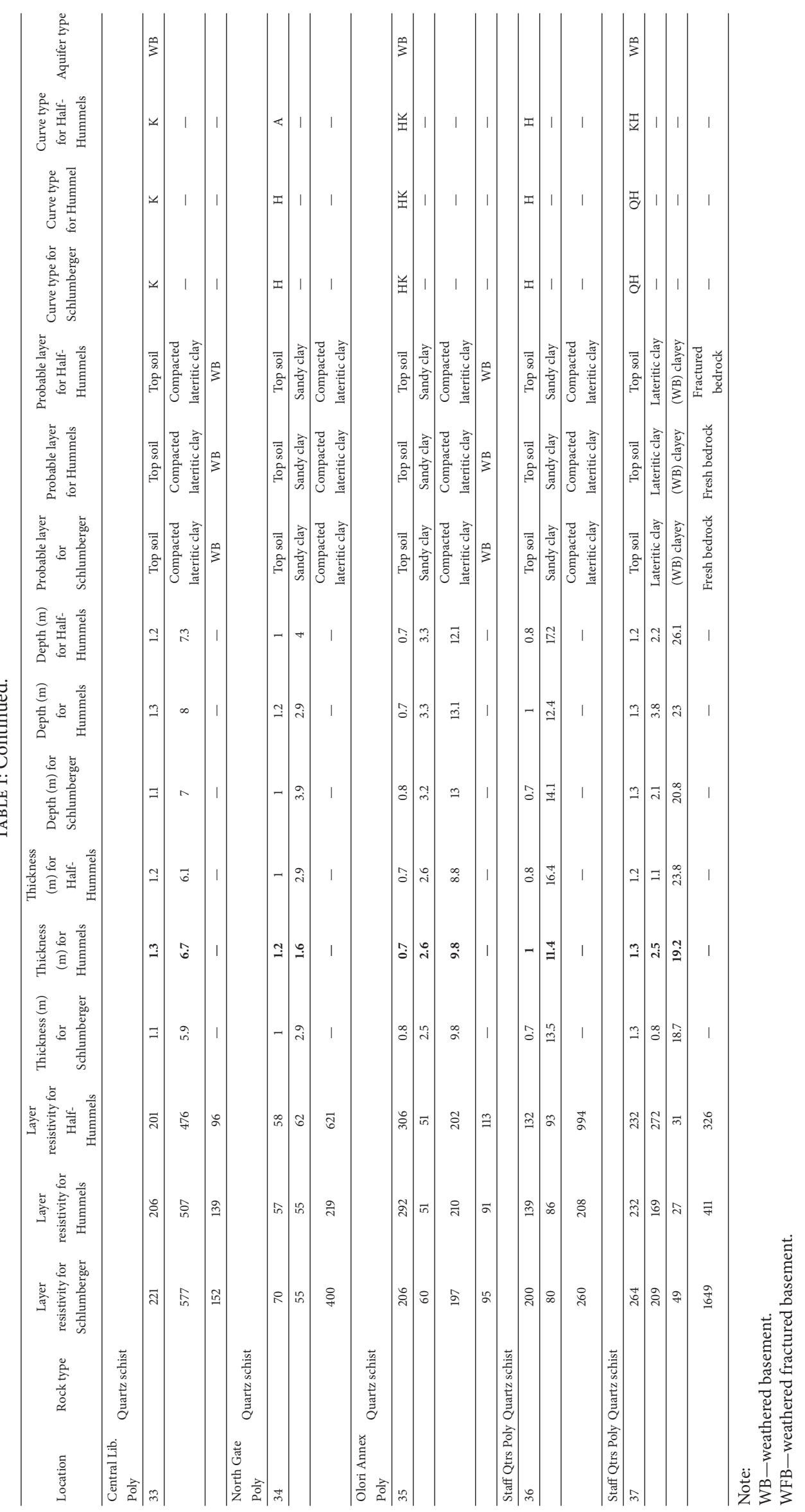



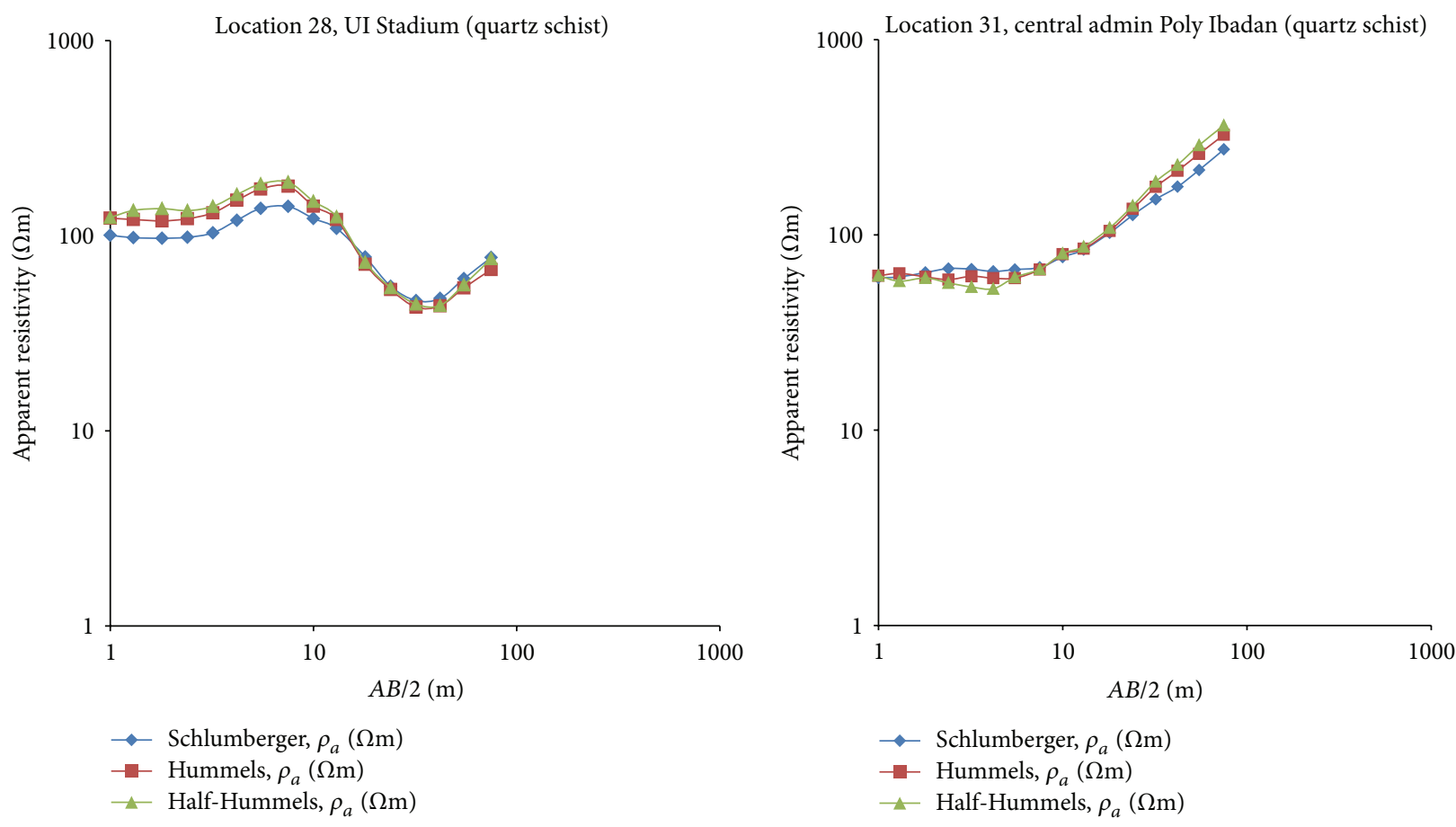

\begin{tabular}{ccccccccc}
\hline \multicolumn{3}{c}{\begin{tabular}{c} 
Conventional \\
\multicolumn{3}{c}{ Schlumberger array }
\end{tabular}} & \multicolumn{3}{c}{ Hummel array } & \multicolumn{3}{c}{ Half-Hummel array } \\
\hline \multicolumn{3}{c}{ RMS error: 2.5} & \multicolumn{3}{c}{ RMS error: 2.5} & \multicolumn{3}{c}{ RMS error: 2.5 } \\
Layers & $\begin{array}{c}\text { Res. } \\
(\Omega \mathrm{m})\end{array}$ & $\begin{array}{c}\text { Depth } \\
(\mathrm{m})\end{array}$ & Layers & $\left.\begin{array}{c}\text { Res. } \\
(\Omega \mathrm{m})\end{array}\right)$ & $\begin{array}{c}\text { Depth } \\
(\mathrm{m})\end{array}$ & $\begin{array}{c}\text { Layers } \\
(\Omega \mathrm{m})\end{array}$ & $\begin{array}{c}\text { Depth } \\
(\mathrm{m})\end{array}$ \\
\hline 1 & 92 & 0.9 & 1 & 114 & 0.8 & 1 & 118 & 1.0 \\
2 & 110 & 2.2 & 2 & 120 & 2.0 & 2 & 185 & 2.7 \\
3 & 210 & 6.0 & 3 & 389 & 4.3 & 3 & 432 & 4.5 \\
4 & 29 & 28.9 & 4 & 30 & 33 & 4 & 28 & 32.2 \\
5 & 331 & & 5 & 377 & & 5 & 3153 & \\
\hline
\end{tabular}

\begin{tabular}{lcccccccc}
\hline \multicolumn{3}{c}{$\begin{array}{c}\text { Conventional } \\
\text { Schlumberger array }\end{array}$} & \multicolumn{3}{c}{ Hummel array } & \multicolumn{3}{c}{ Half-Hummel array } \\
\hline \multicolumn{3}{c}{ RMS error: 1.8} & \multicolumn{3}{c}{ RMS error: 1.5} & \multicolumn{3}{c}{ RMS error: 2.1} \\
Layers & $\begin{array}{c}\text { Res. } \\
(\Omega \mathrm{m})\end{array}$ & $\begin{array}{c}\text { Depth } \\
(\mathrm{m})\end{array}$ & Layers & $\begin{array}{c}\text { Res. } \\
(\Omega \mathrm{m})\end{array}$ & $\begin{array}{c}\text { Depth } \\
(\mathrm{m})\end{array}$ & $\begin{array}{c}\text { Layers } \\
(\Omega \mathrm{m})\end{array}$ & $\begin{array}{c}\text { Resth } \\
(\mathrm{m})\end{array}$ \\
\hline 1 & 60 & 1.2 & 1 & 61 & 1.2 & 1 & 32 & 1.3 \\
2 & 74 & 13 & 2 & 62 & 9.8 & 2 & 50 & 7.3 \\
3 & 738 & & 3 & 910 & & 3 & 864 & \\
\hline
\end{tabular}

(a)

(b)

FIGURE 5: Comparison of results obtained from the interpretation of field data collected using the different array methods at VES stations on quartz schist for (a) location 28, University of Ibadan, and (b) location 31, the Polytechnic Ibadan.

locations with augen gneiss lithology have maximum number of four layers. The range of weathered layer resistivity is between 16 and $561 \Omega \mathrm{m}$, with overburden thickness between 5.0 and $39.9 \mathrm{~m}$; the basement resistivity ranges between 46 and $13333 \Omega \mathrm{m}$ for the different array methods employed. For locations with quartz schist lithology, the maximum number of layers observed was five. The range of weathered layer resistivity is between 27 and $250 \Omega \mathrm{m}$, with overburden thickness between 7.2 and $32.9 \mathrm{~m}$; the basement resistivity ranges between 152 and $3153 \Omega \mathrm{m}$ for the different array methods employed.

Similarities were observed between the conventional Schlumberger array, Hummel array, and the Half-Hummel array methods employed as the interpretation obtained from the field data resulted in the same number of subsurface layers. Although, variation occurred in the nature of the bedrock (fractured or fresh) interpreted for conventional Schlumberger and modified Schlumberger array methods in locations 10,21,22, and 26 (Table 1), this may be due to structural variations and differential weathering within the bedrock. However, overall similarities can be established between the results of data obtained using the conventional Schlumberger array, Hummel array, and the Half-Hummel array methods at all vertical electrical sounding stations within the area of study. The significant variation in overburden thickness (depth to basement), recorded for the conventional Schlumberger array and modified Schlumberger array methods in some VES locations such as 3, 8, 17, 18, 21, 28, 29, and 37 (Table 1), was largely due to differential weathering of the bedrock. Also, the significant variation in the values of basement resistivity recorded for the conventional Schlumberger array and modified Schlumberger array methods at some VES locations such as 21, 22, 27, and 37 (Table 1) may be due to differential weathering within the bedrock as well as varying degree of saturation of the bedrock unit from one point to another.

6.2. Comparison of Conventional and Modified Schlumberger Arrays Results. The results obtained from the different array 


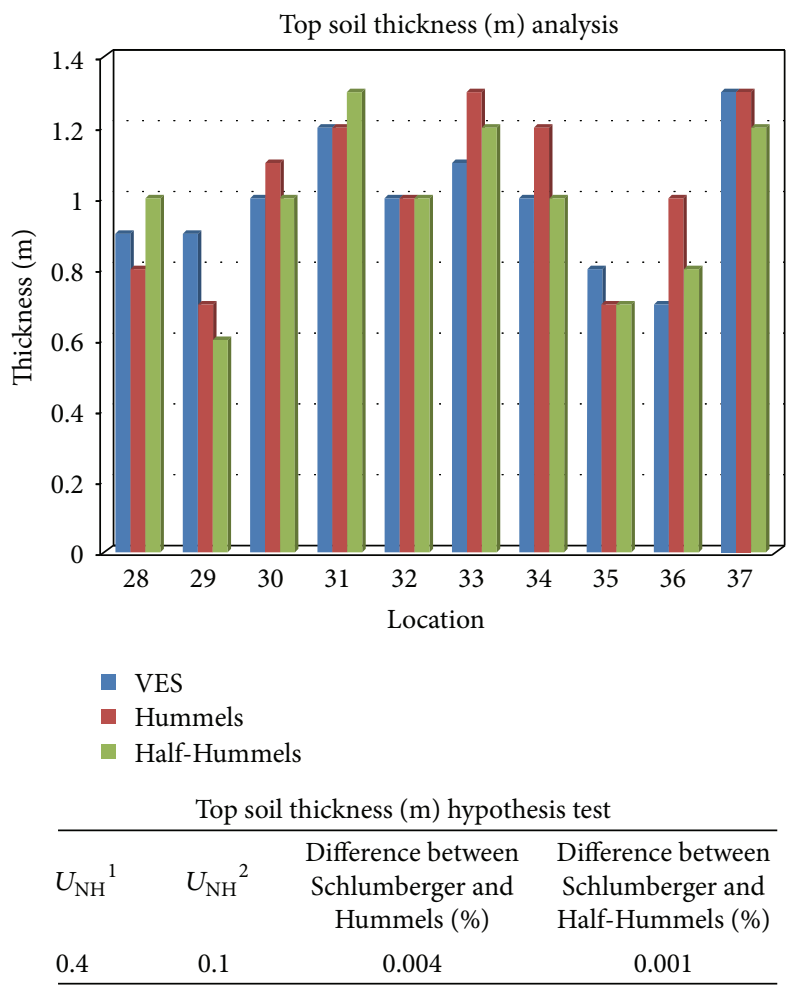

(a)

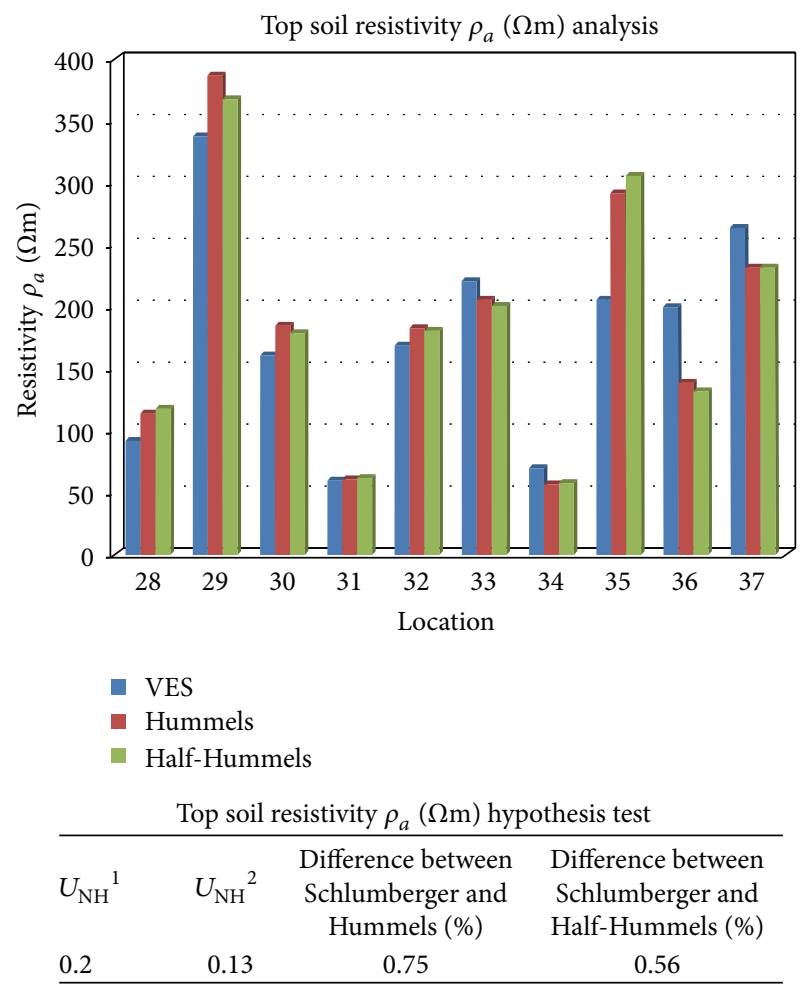

(b)

FiguRE 6: Bar chart and statistical test of hypothesis table for the different array methods comparing (a) topsoil thickness and (b) topsoil resistivity, for locations on quartz schist.

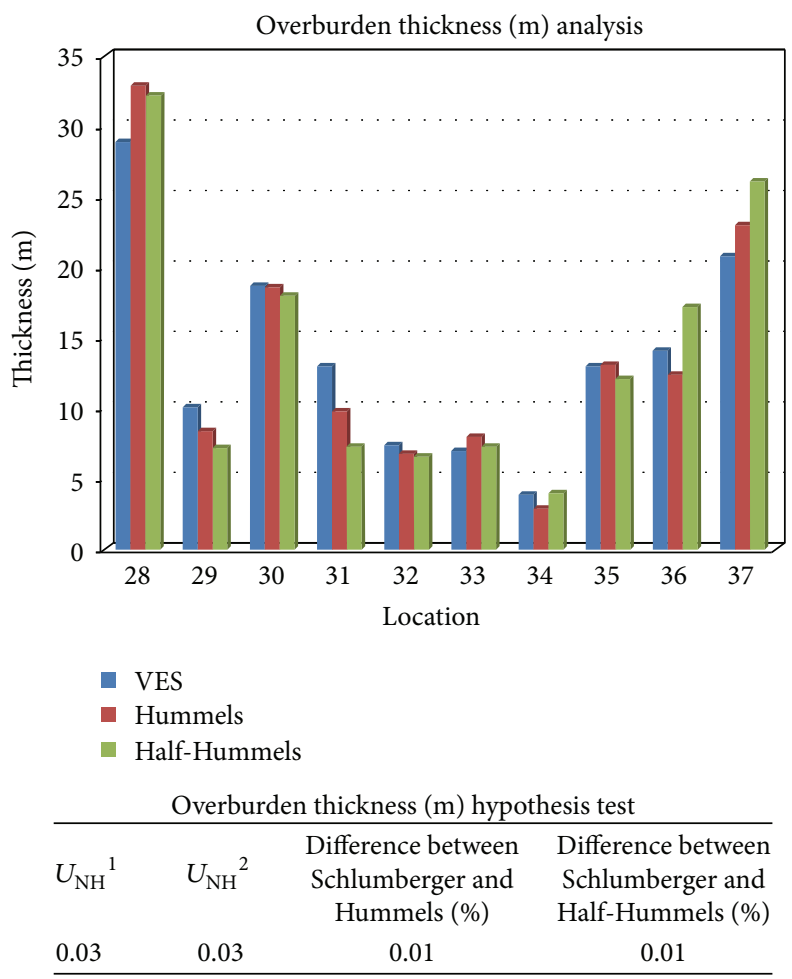

FIGURE 7: Bar chart and statistical test of hypothesis table for the different array methods comparing Overburden thickness for locations on quartz schist. 


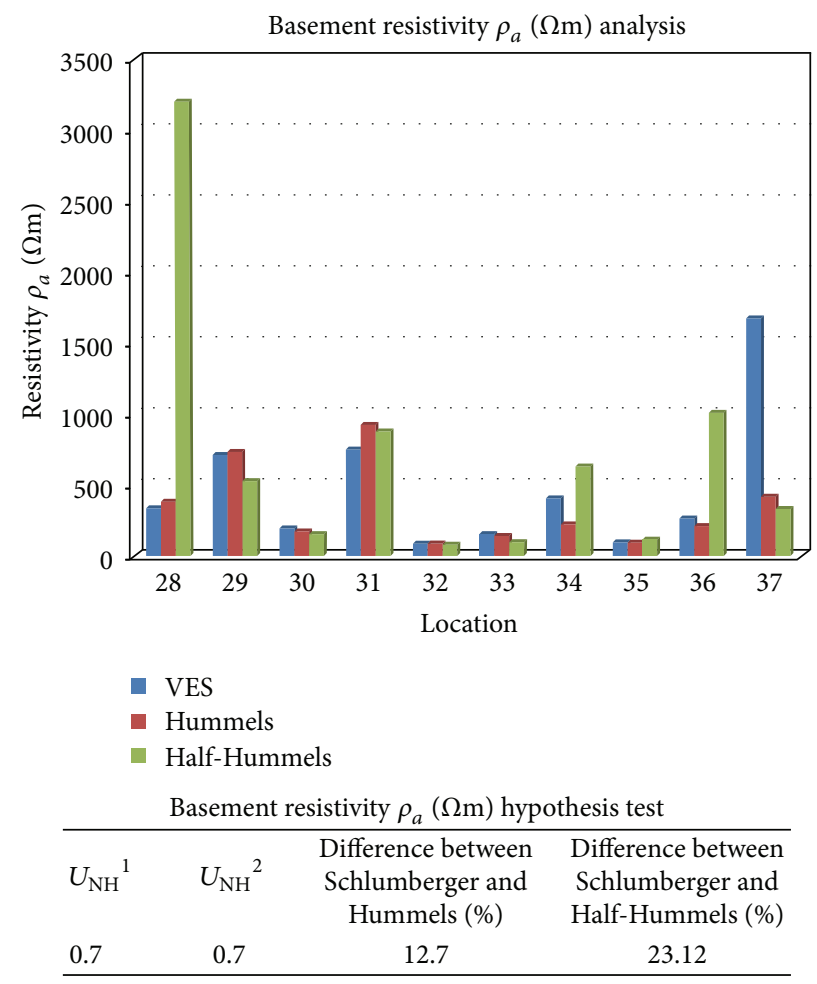

FIGURE 8: Bar chart and statistical test of hypothesis table for the different array methods comparing basement resistivity for locations on quartz schist.

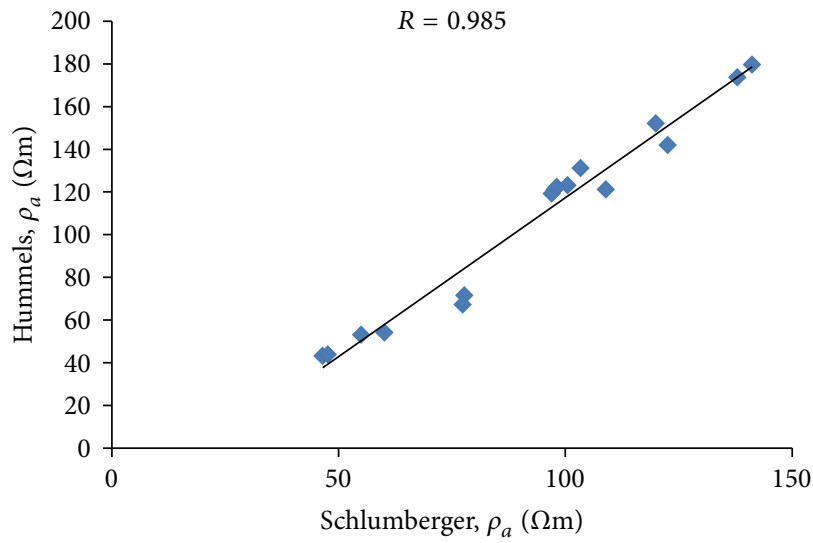

(a)

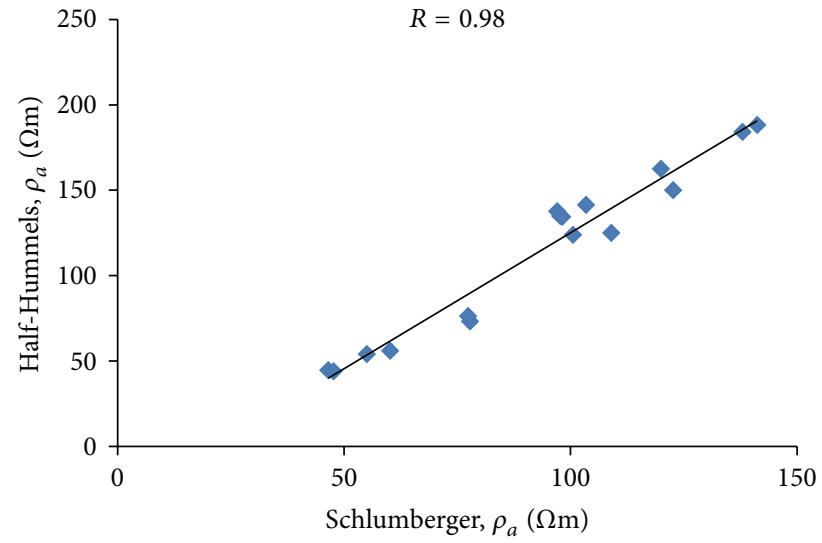

(b)

FIgURE 9: Statistical plot of apparent resistivity data for location 28 (quartz schist) (a) Hummel against conventional Schlumberger (VES) and (b) "Half-Hummel" against conventional Schlumberger (VES).

methods at each VES stations within the study area were compared visually, through the use of statistical correlation plots and test of hypothesis.

Figures 5(a) and 5(b) show the similarities in the results of interpretation of the field data obtained from two different VES stations across quartz schist (locations 28 and 31). Figure 6 shows that the topsoil resistivity and thickness obtained from the conventional Schlumberger and modified Schlumberger arrays were virtually the same for VES stations on quartz schist while the layer parameters significantly correlate for the VES stations across the same lithology (Figure 7). Also, Figure 8 shows that the basement resistivity values from the different arrays are very similar for the quartz schist terrain. Figures 9 and 10 represent the statistical correlation plots of the apparent resistivity data obtained at the same stations as in Figures 5(a) and 5(b), respectively. The plots show a good linear relationship between apparent resistivity values determined from the different arrays with coefficient of 


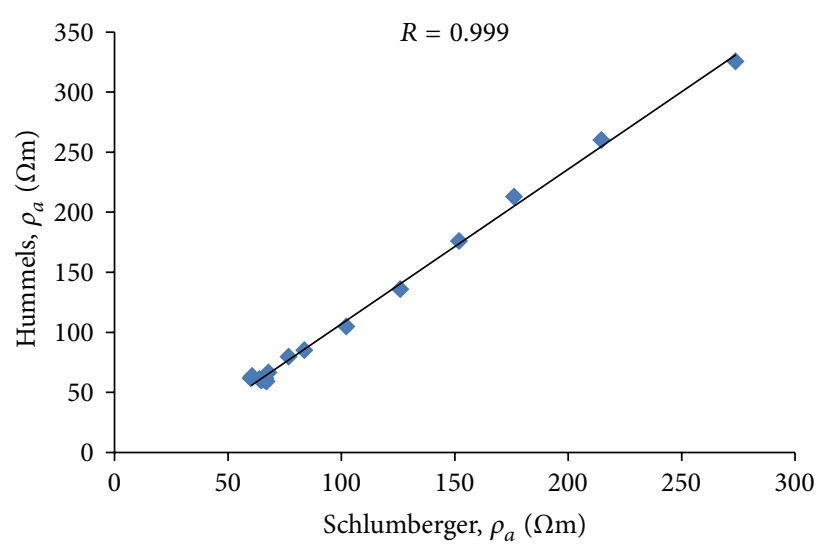

(a)

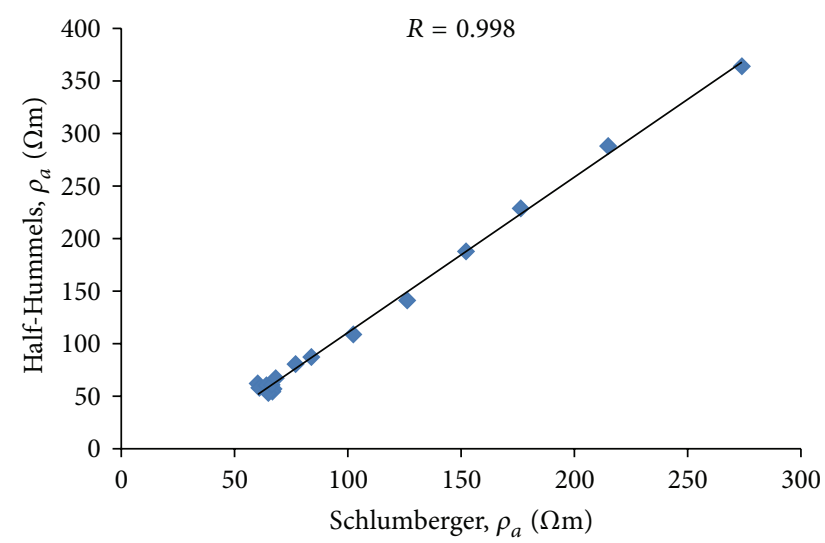

(b)

FIGURE 10: Statistical plot of apparent resistivity data for location 31 (quartz schist) (a) Hummel against conventional Schlumberger (VES) and (b) "Half-Hummel" against conventional Schlumberger (VES).

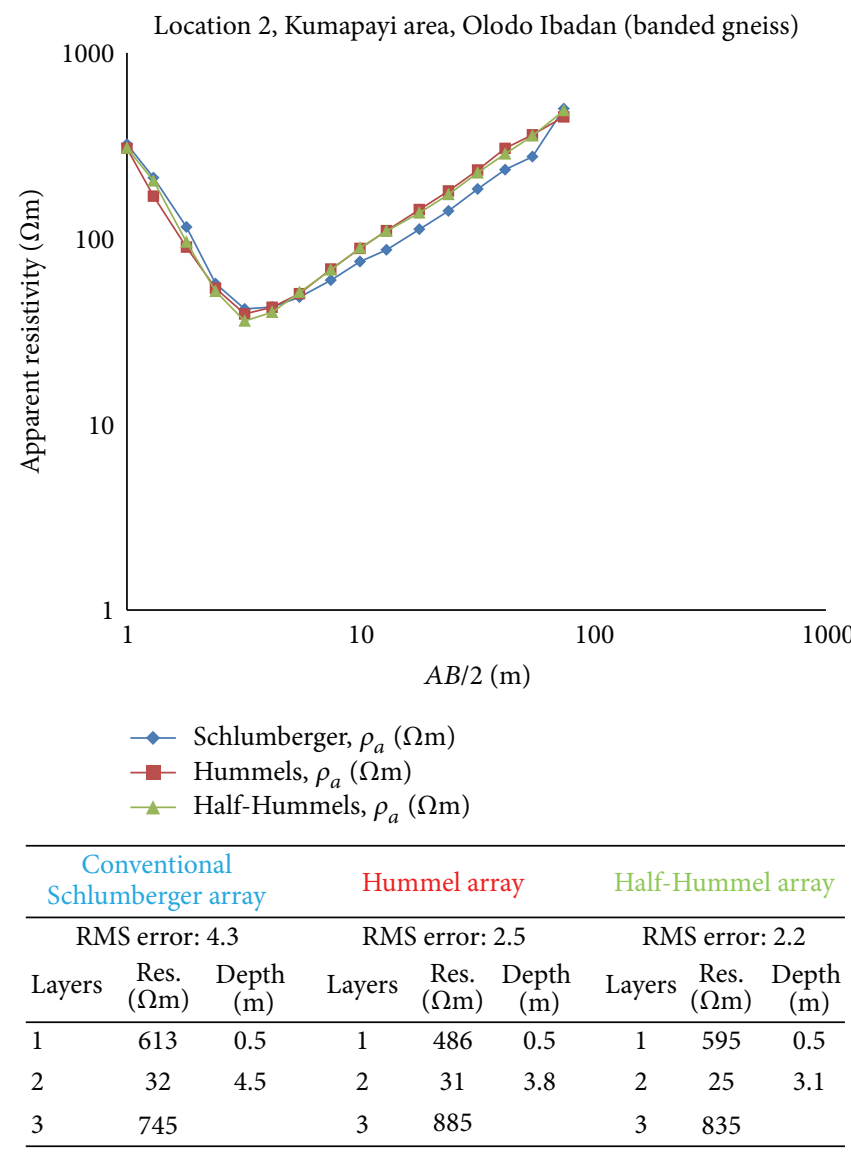

(a)

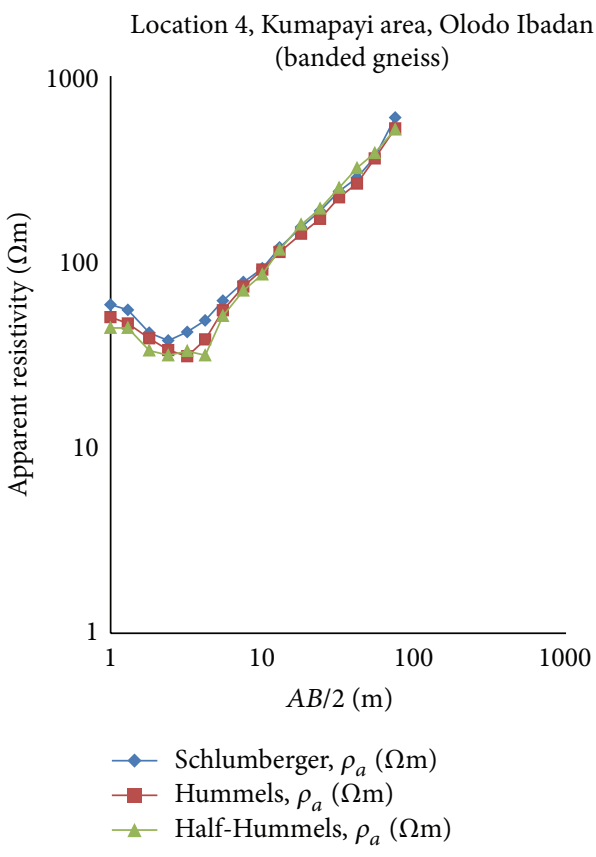

\begin{tabular}{ccccccccc}
\hline \multicolumn{3}{c}{\begin{tabular}{c} 
Conventional \\
\multicolumn{3}{c}{ Schlumberger array }
\end{tabular}} & \multicolumn{3}{c}{ Hummel array } & \multicolumn{3}{c}{ Half-Hummel array } \\
\hline \multicolumn{3}{c}{ RMS error: 3.8 } & \multicolumn{3}{c}{ RMS error: 3.3 } & \multicolumn{3}{c}{ RMS error: 3.3 } \\
Layers & $\begin{array}{c}\text { Res. } \\
(\Omega \mathrm{m})\end{array}$ & $\begin{array}{c}\text { Depth } \\
(\mathrm{m})\end{array}$ & Layers & $\left.\begin{array}{c}\text { Res. } \\
(\Omega \mathrm{m})\end{array}\right)$ & $\begin{array}{c}\text { Depth } \\
(\mathrm{m})\end{array}$ & $\begin{array}{c}\text { Layers } \\
\text { Res. } \\
(\Omega \mathrm{m})\end{array}$ & $\begin{array}{c}\text { Depth } \\
(\mathrm{m})\end{array}$ \\
\hline 1 & 73 & 0.7 & 1 & 67 & 0.6 & 1 & 53 & 0.7 \\
2 & 25 & 2.8 & 2 & 21 & 2.7 & 2 & 20 & 2.6 \\
3 & 982 & & 3 & 1019 & & 3 & 1338 & \\
\hline
\end{tabular}

(b)

FIGURE 11: Comparison of results obtained from the interpretation of field data collected using the different array methods at VES stations on banded gneiss for (a) location 2, Olodo Ibadan, and (b) location 4, Olodo Ibadan.

correlation $(R)$ for the Hummel/conventional Schlumberger and Half-Hummel/conventional Schlumberger arrays ranging between 0.98 and 0.99 .

Figures 11(a) and 11(b) show the similarities in the results of interpretation of the field data obtained from two different
VES stations across banded gneiss (locations 2 and 4). Figure 12 shows that the topsoil resistivity and thickness determined from conventional and modified Schlumberger arrays were virtually the same for the VES stations on banded gneiss. The layer parameters obtained show some 


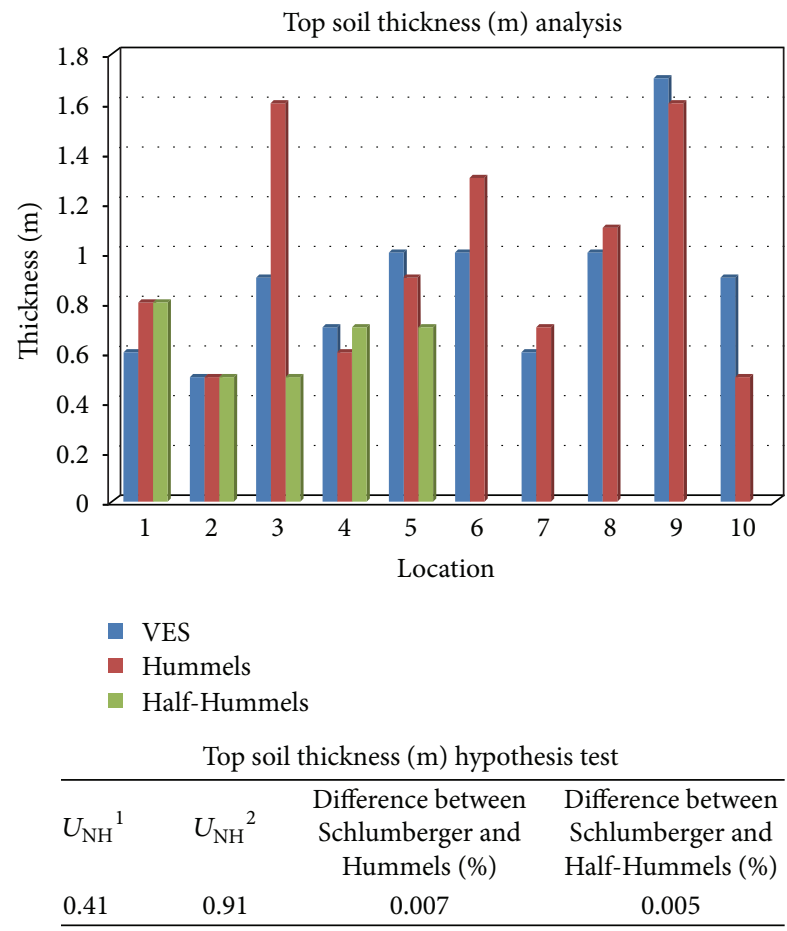

(a)

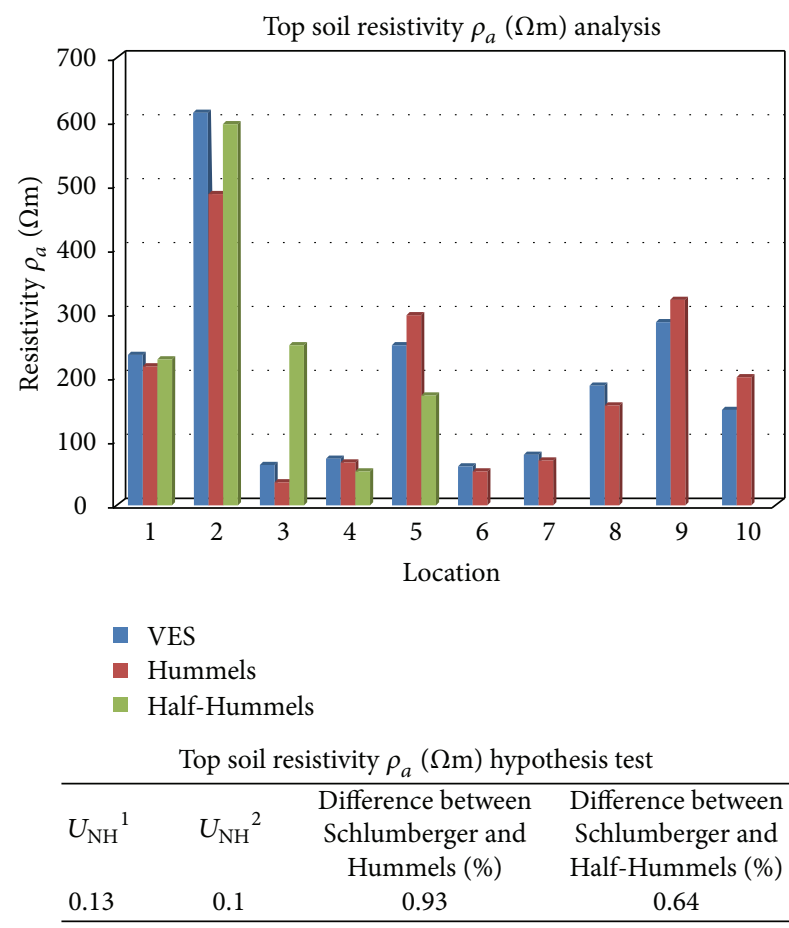

(b)

FIGURE 12: Bar chart and statistical test of hypothesis table for the different array methods comparing (a) topsoil thickness and (b) topsoil resistivity, for stations on banded gneiss.

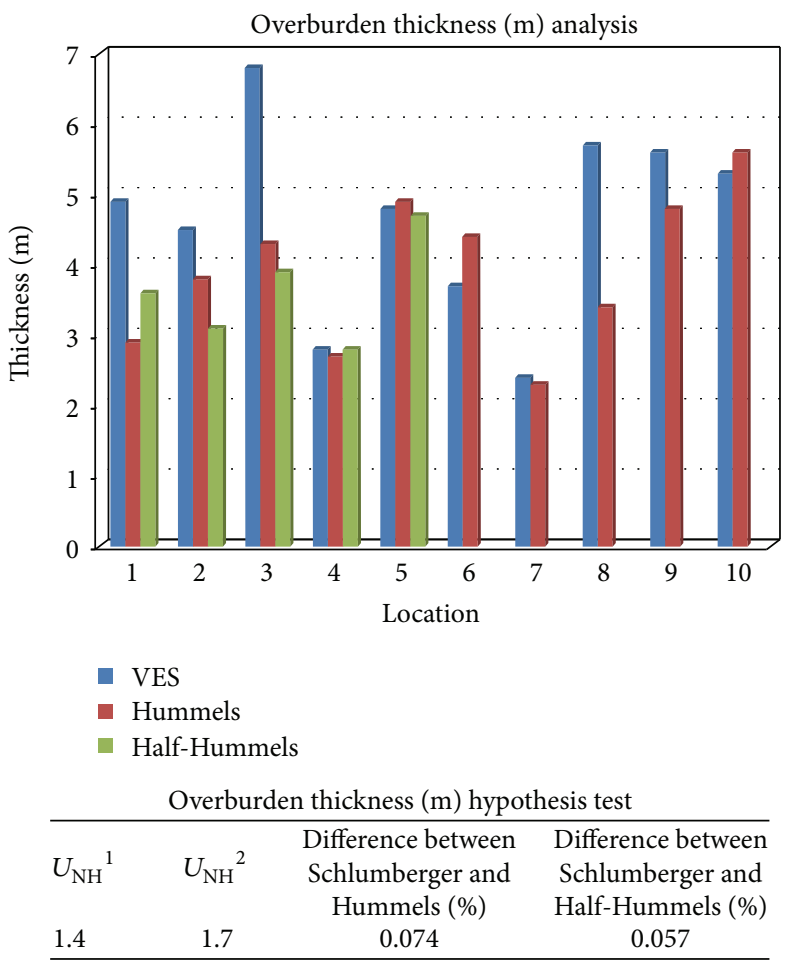

FIGURE 13: Bar chart and statistical test of hypothesis table for the different array methods comparing overburden thickness for locations on banded gneiss. 


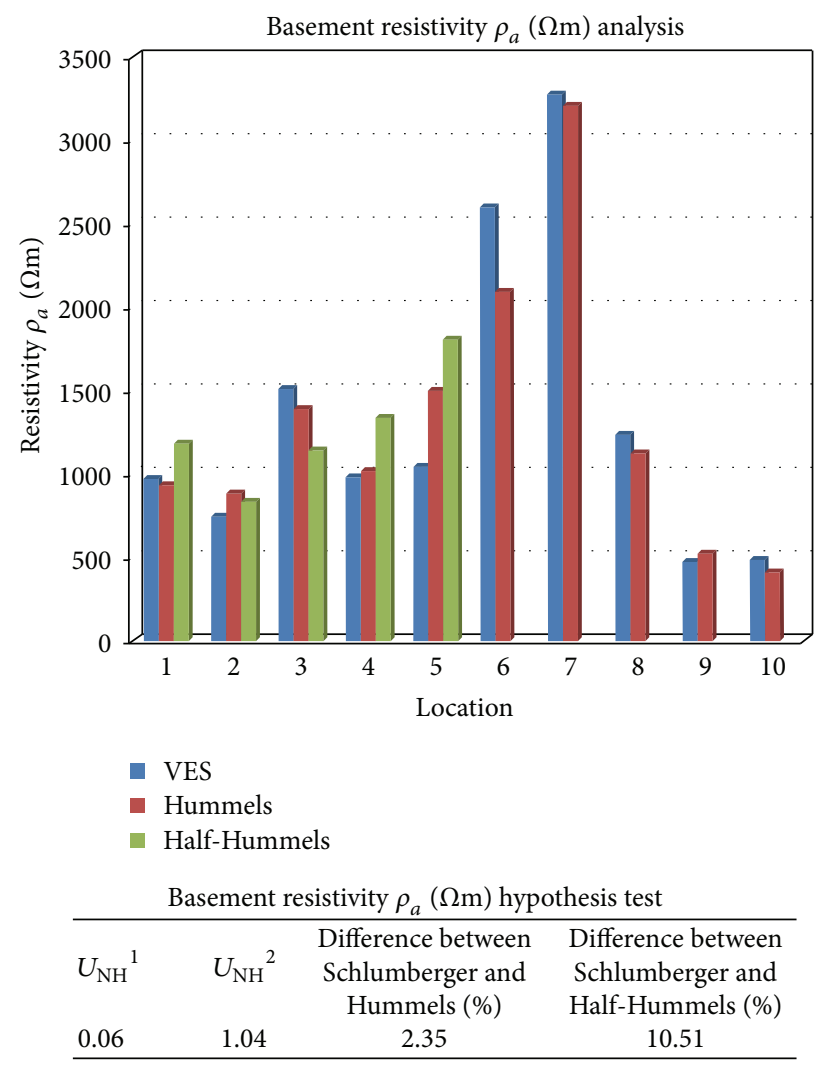

FIGURE 14: Bar chart and statistical test of hypothesis table for the different array methods comparing basement resistivity for locations on banded gneiss.

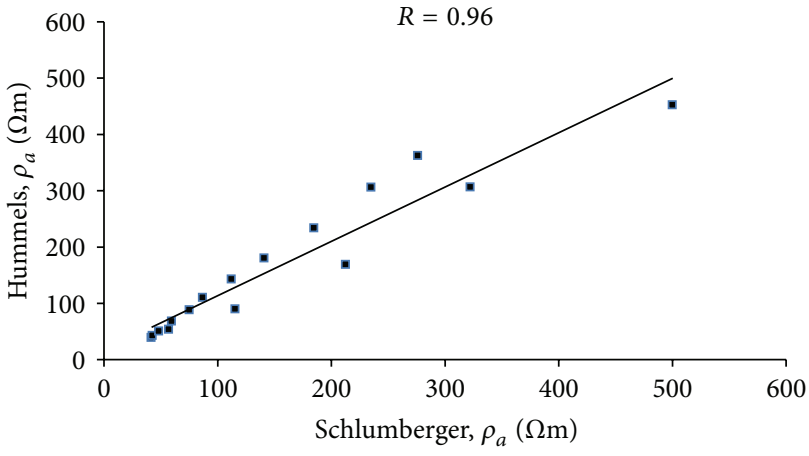

(a)

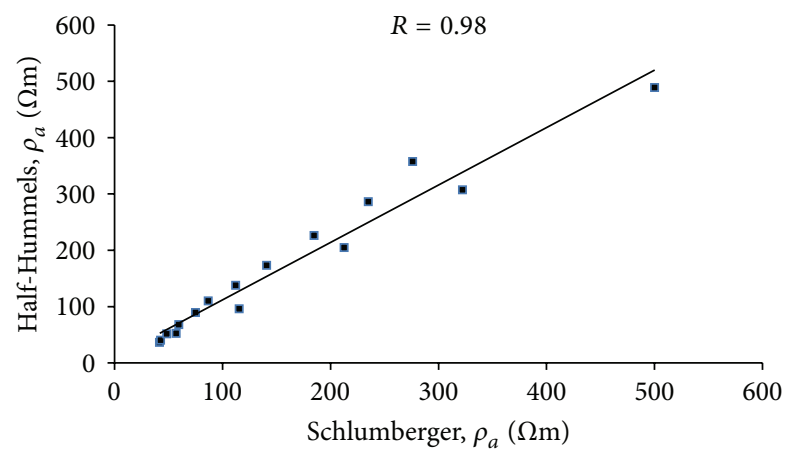

(b)

FIGURE 15: Statistical plot of apparent resistivity data for location 2 (banded gneiss) (a) Hummel against conventional Schlumberger (VES) and (b) "Half-Hummel" against conventional Schlumberger (VES).

degree of correlation for the VES stations across the same lithology (Figure 13). Also, Figure 14 shows that the basement resistivity values from the different arrays are very similar for the banded gneiss terrain. Figures 15 and 16 show the statistical correlation plots of the apparent resistivity data obtained at the same stations. The plots show a good linear relationship between apparent resistivity values determined from the different arrays with coefficient of correlation $(R)$ for the Hummel/conventional Schlumberger and Half-Hummel/conventional Schlumberger arrays ranging between 0.96 and 0.99 .
The similarities in the results of interpretation of the field data obtained from two different VES stations (locations 22 and 24) across augen gneiss terrain using the different array methods are as shown in Figures 17(a) and 17(b). Figure 18 shows that the topsoil resistivity and thickness determined from conventional Schlumberger and modified Schlumberger arrays were virtually the same for VES stations on augen gneiss. The layer parameters obtained show some degree of correlation for the VES stations across the same lithology (Figure 19). Also, Figure 20 shows that the basement resistivity values for the different arrays are very 


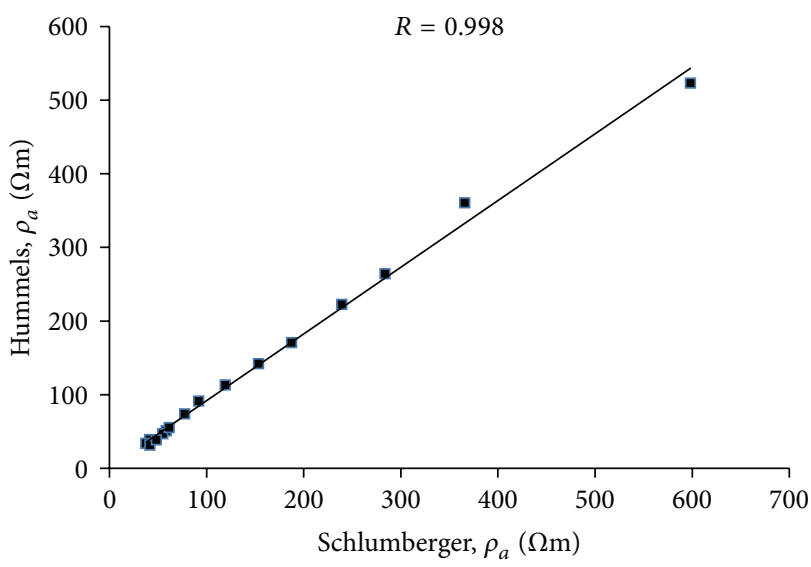

(a)

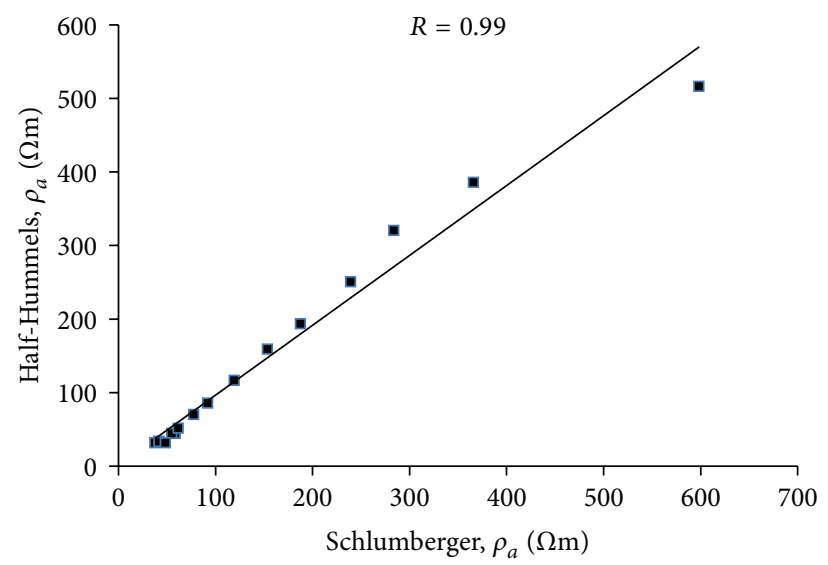

(b)

FIGURE 16: Statistical plot of apparent resistivity data for location 4 (banded gneiss) (a) Hummel against conventional Schlumberger (VES) and (b) "Half-Hummel" against conventional Schlumberger (VES).

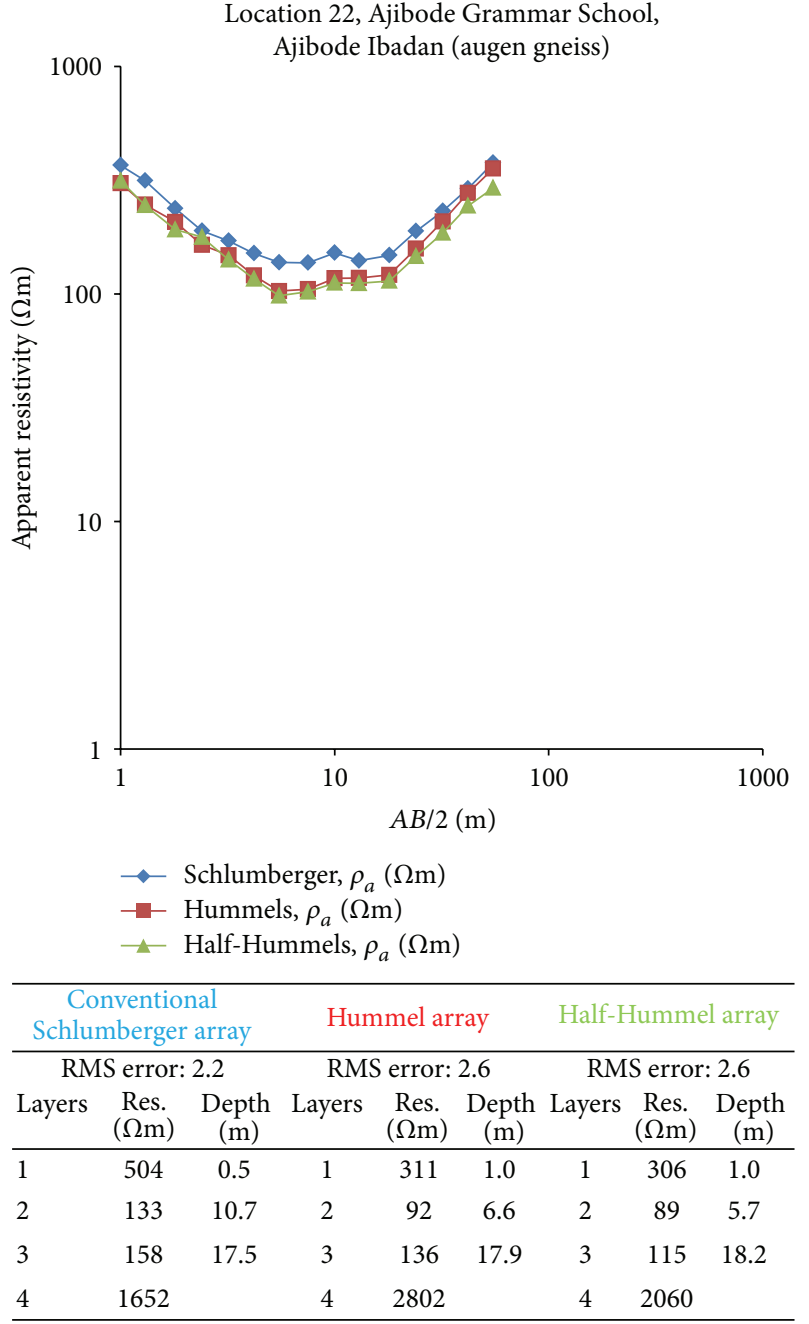

(a)

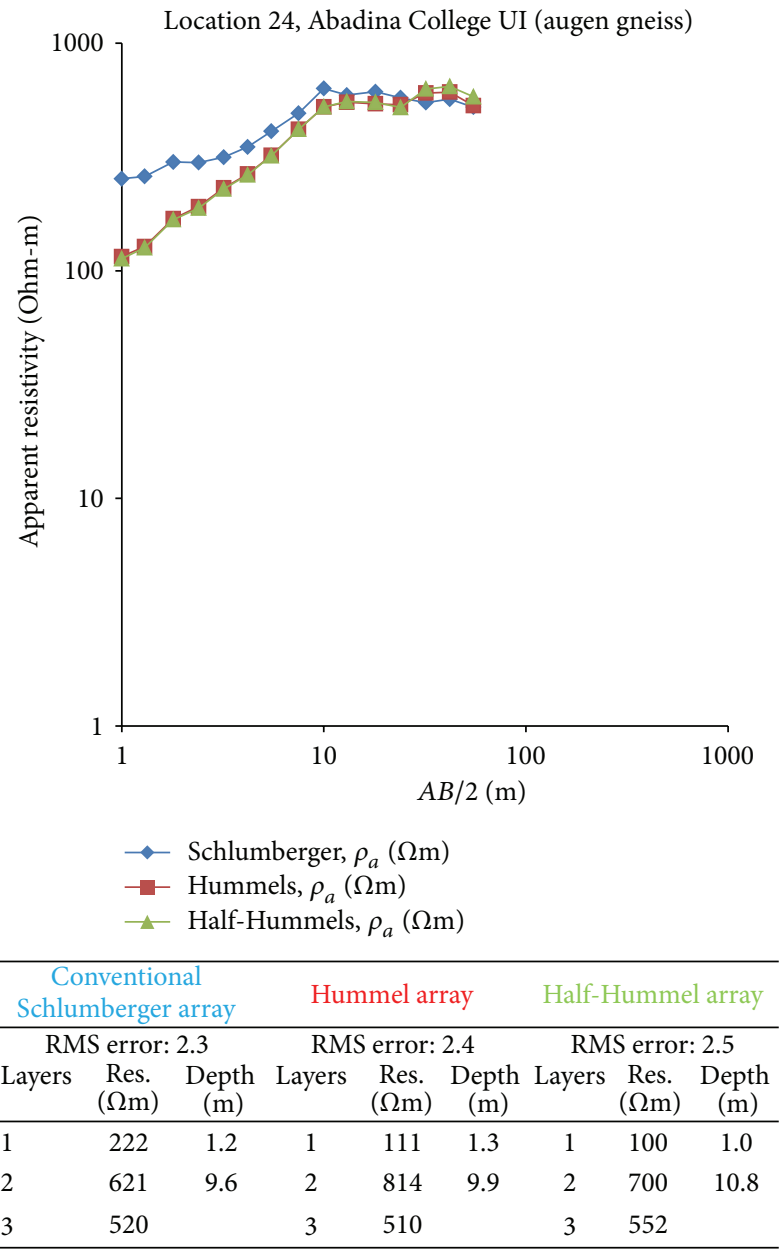

(b)

FIGURE 17: Comparison of results obtained from the interpretation of field data collected using the different array methods at VES stations on augen gneiss for (a) location 22, Ajibode Ibadan, and (b) location 24, Ajibode Ibadan. 

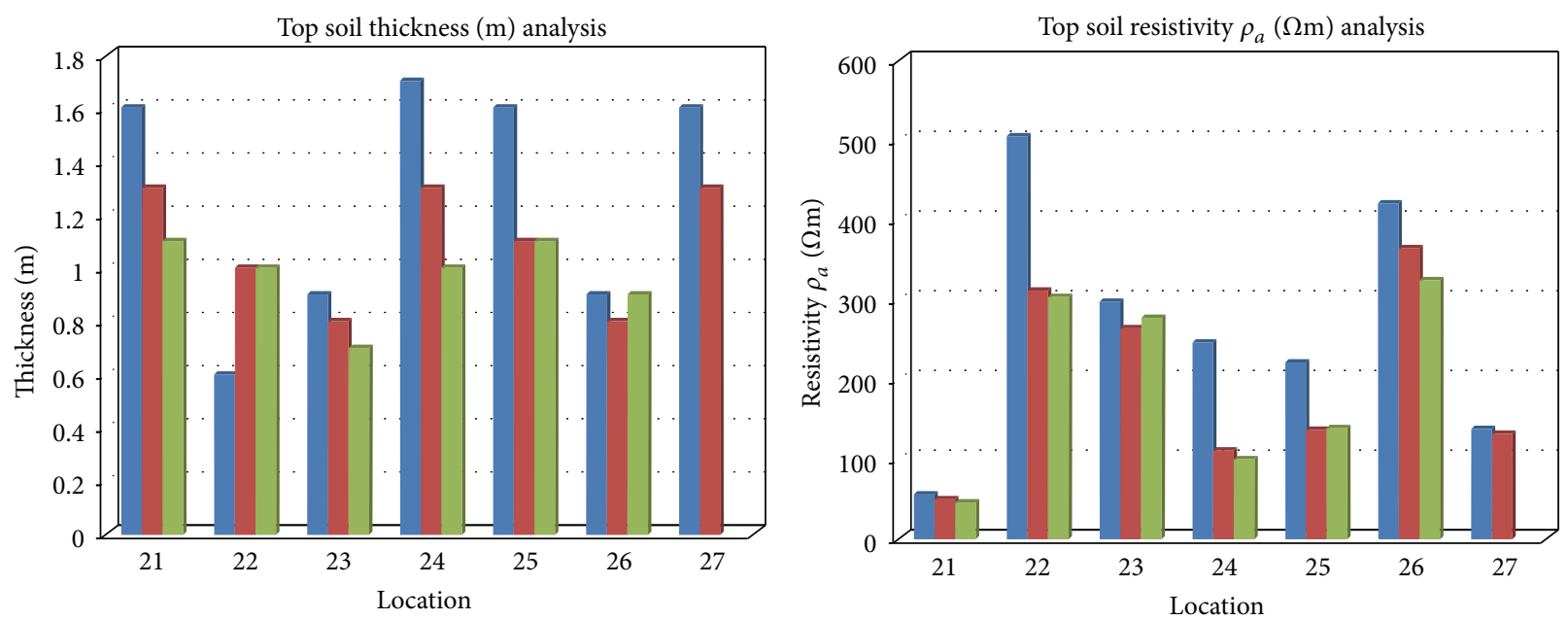

VES
- Hummels
- Half-Hummels

\begin{tabular}{cccc}
\multicolumn{4}{c}{ Top soil thickness (m) hypothesis test } \\
\hline$U_{\mathrm{NH}}{ }^{1}$ & $U_{\mathrm{NH}}{ }^{2}$ & $\begin{array}{c}\text { Difference between } \\
\text { Schlumberger and } \\
\text { Hummels (\%) }\end{array}$ & $\begin{array}{c}\text { Difference between } \\
\text { Schlumberger and } \\
\text { Half-Hummels (\%) }\end{array}$ \\
0.93 & 1.4 & 0.013 & 0.015
\end{tabular}

(a)

VES

- Hummels

Half-Hummels

\begin{tabular}{cccc}
\multicolumn{4}{c}{ Top soil resistivity $\rho_{a}(\Omega \mathrm{m})$ hypothesis test } \\
\hline$U_{\mathrm{NH}}{ }^{1}$ & $U_{\mathrm{NH}}{ }^{2}$ & $\begin{array}{c}\text { Difference between } \\
\text { Schlumberger and }\end{array}$ & $\begin{array}{c}\text { Difference between } \\
\text { Schlumberger and } \\
1\end{array}$ \\
& 1.2 & Hummels (\%) & Half-Hummels (\%) \\
\hline
\end{tabular}

(b)

FIGURE 18: Bar chart and statistical test of hypothesis table for the different array methods comparing (a) topsoil thickness and (b) topsoil resistivity, for stations on augen gneiss.

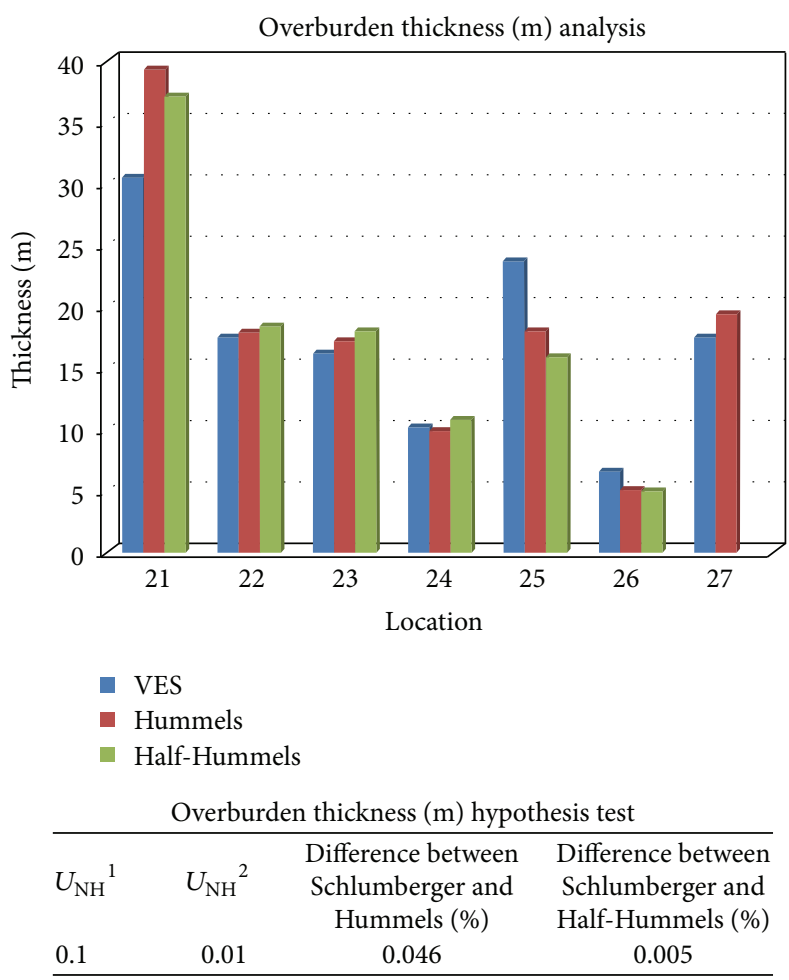

FIGURE 19: Bar chart and statistical test of hypothesis table for the different array methods comparing overburden thickness for locations on augen gneiss. 


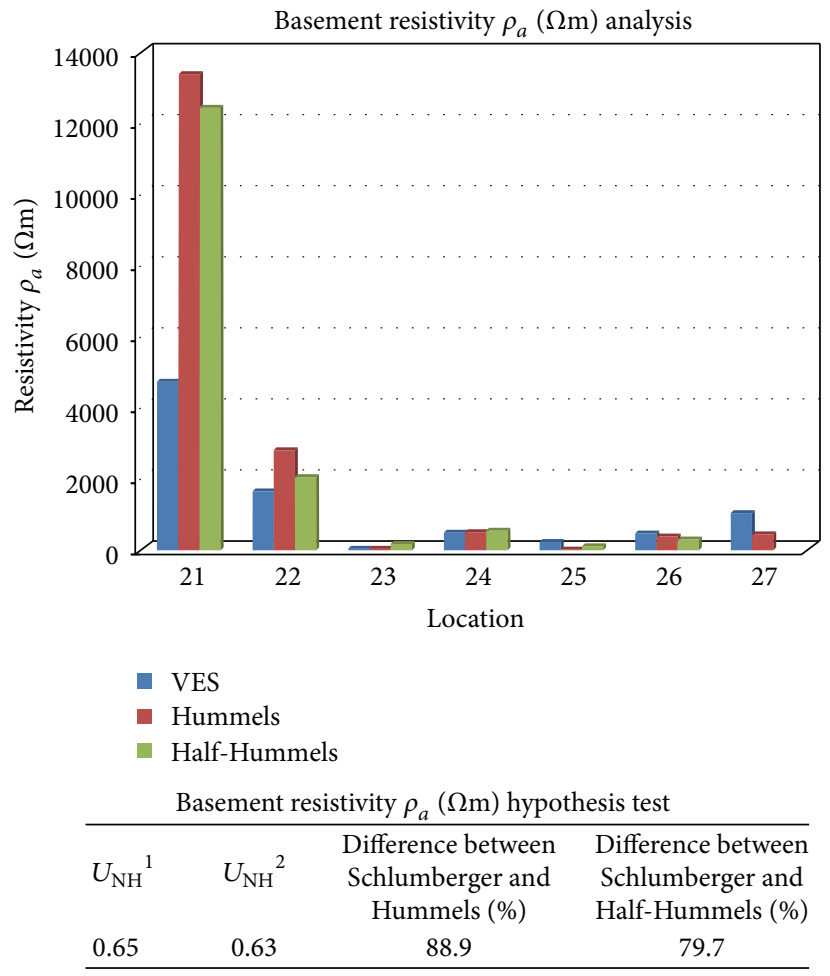

FIGURE 20: Bar chart and statistical test of hypothesis table for the different array methods comparing basement resistivity for locations on augen gneiss.

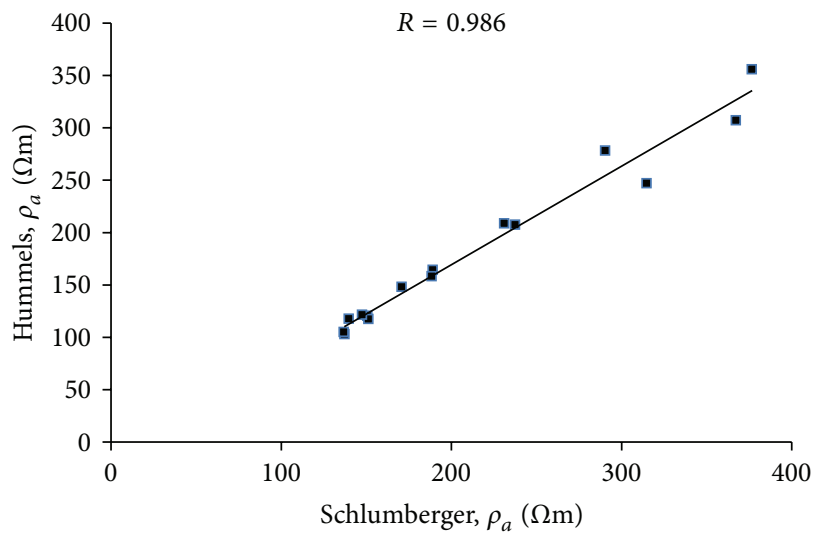

(a)

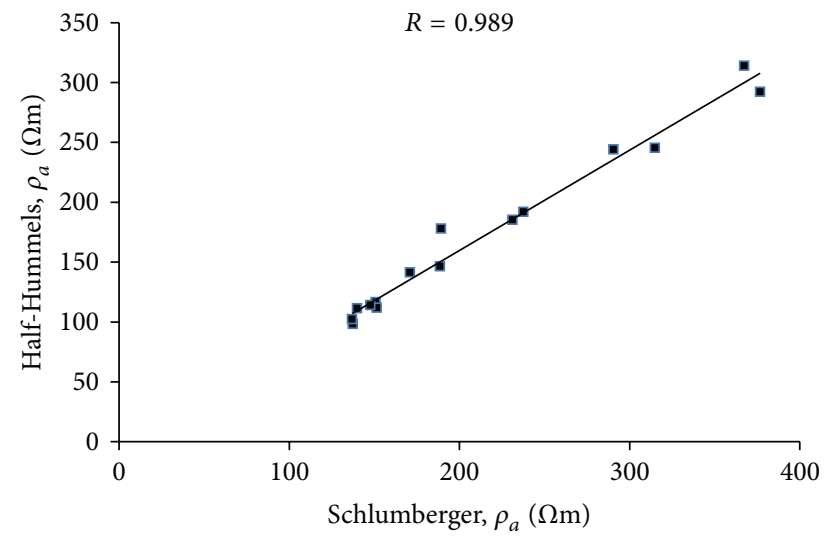

(b)

FIGURE 21: Statistical plot of apparent resistivity data for location 22 (augen gneiss) (a) Hummel against conventional Schlumberger (VES) and (b) "Half-Hummel" against conventional Schlumberger (VES).

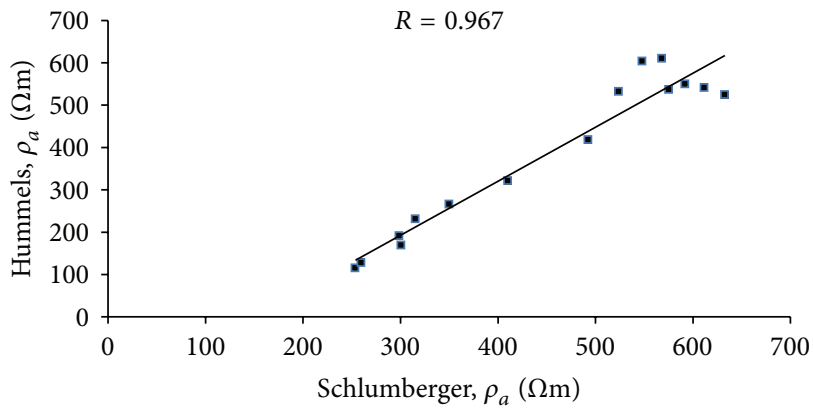

(a)

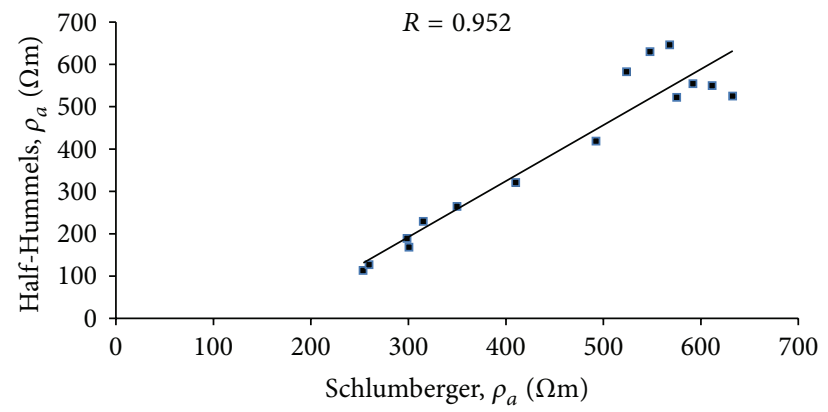

(b)

FIGURE 22: Statistical plot of apparent resistivity data for location 24 (augen gneiss) (a) Hummel against conventional Schlumberger (VES) and (b) "Half-Hummel" against conventional Schlumberger (VES). 


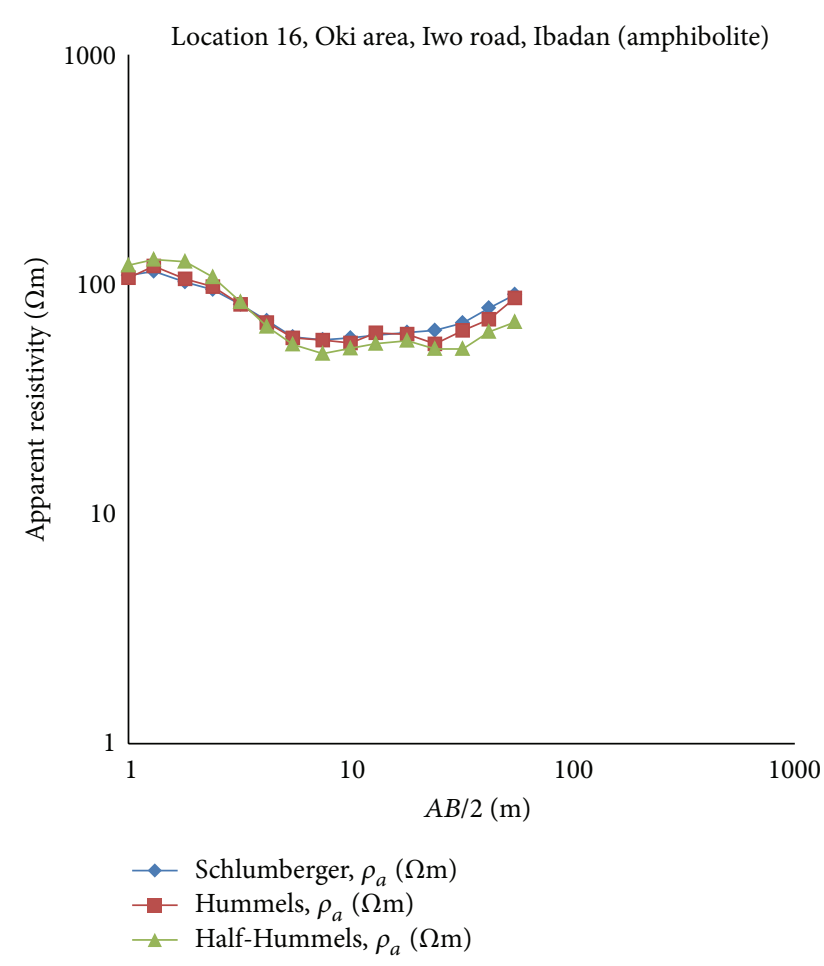

\begin{tabular}{ccccccccc}
\hline \multicolumn{3}{c}{$\begin{array}{c}\text { Conventional } \\
\text { Schlumberger array }\end{array}$} & \multicolumn{3}{c}{ Hummel array } & \multicolumn{3}{c}{ Half-Hummel array } \\
\hline \multicolumn{3}{c}{ RMS error: 2.5} & \multicolumn{3}{c}{ RMS error: 3.2 } & \multicolumn{3}{c}{ RMS error: 2.8} \\
Layers & $\begin{array}{c}\text { Res. } \\
(\Omega \mathrm{m})\end{array}$ & $\begin{array}{c}\text { Depth } \\
(\mathrm{m})\end{array}$ & Layers & $\begin{array}{c}\text { Res. } \\
(\Omega \mathrm{m})\end{array}$ & $\begin{array}{c}\text { Depth } \\
(\mathrm{m})\end{array}$ & $\begin{array}{c}\text { Layers } \\
\text { Res. } \\
(\Omega \mathrm{m})\end{array}$ & $\begin{array}{c}\text { Depth } \\
(\mathrm{m})\end{array}$ \\
\hline 1 & 125 & 1.1 & 1 & 125 & 1.2 & 1 & 139 & 1.4 \\
2 & 53 & 8.5 & 2 & 51 & 9.9 & 2 & 44 & 7.8 \\
3 & 85 & & 3 & 81 & & 3 & 65 & \\
\hline
\end{tabular}

(a)

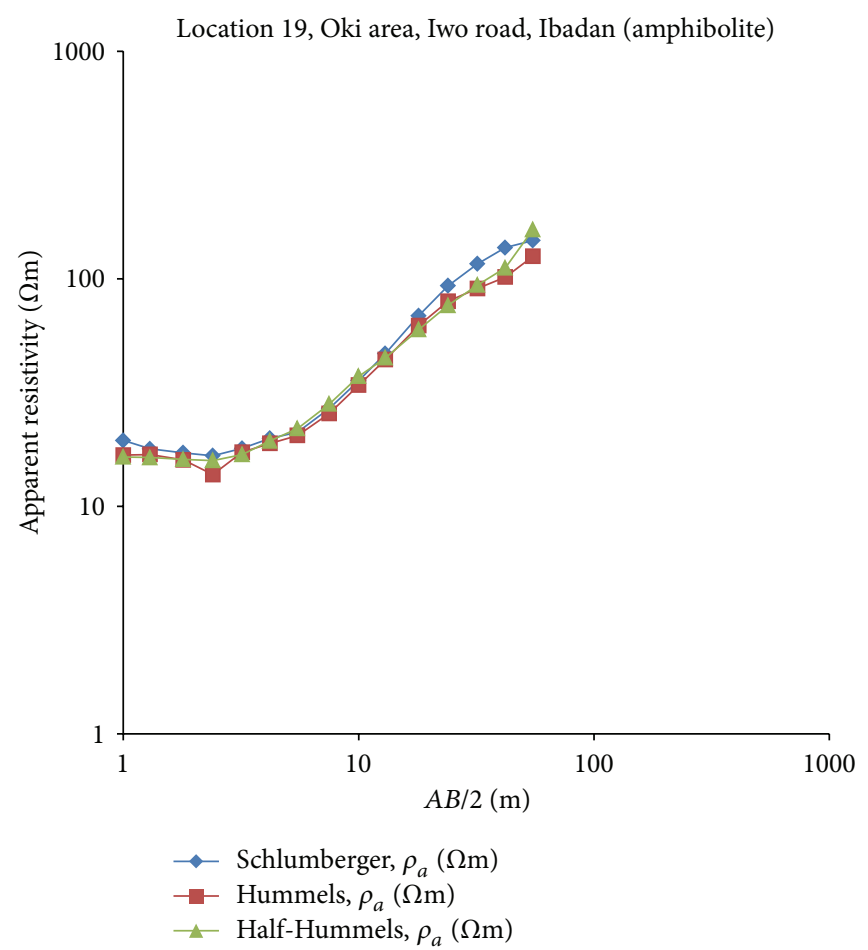

\begin{tabular}{|c|c|c|c|c|c|c|c|c|}
\hline \multicolumn{3}{|c|}{$\begin{array}{c}\text { Conventional } \\
\text { Schlumberger array }\end{array}$} & \multicolumn{3}{|c|}{ Hummel array } & \multicolumn{3}{|c|}{ Half-Hummel array } \\
\hline \multicolumn{3}{|c|}{ RMS error: 2.7} & \multicolumn{3}{|c|}{ RMS error: 2.5} & \multicolumn{3}{|c|}{ RMS error: 2.3} \\
\hline Layers & $\begin{array}{l}\text { Res } \\
(\Omega \mathrm{m})\end{array}$ & $\begin{array}{l}\text { Depth } \\
\text { (m) }\end{array}$ & Layers & $\begin{array}{l}\text { Res } \\
(\Omega \mathrm{m})\end{array}$ & $\begin{array}{l}\text { Depth } \\
\text { (m) }\end{array}$ & Layers & $\begin{array}{l}\text { Res } \\
(\Omega \mathrm{m})\end{array}$ & $\begin{array}{l}\text { Depth } \\
\text { (m) }\end{array}$ \\
\hline 1 & 20 & 0.8 & 1 & 17 & 1.0 & 1 & 17 & 0.6 \\
\hline 2 & 13 & 3.4 & 2 & 12 & 3.3 & 2 & 15 & 3.8 \\
\hline 3 & 458 & & 3 & 264 & & 3 & 298 & \\
\hline
\end{tabular}

(b)

FIGURE 23: Comparison of results obtained from the interpretation of field data collected using the different array methods at VES stations on amphibolite for (a) location 16, Oki Ibadan, and (b) location 19, Oki Ibadan.

similar for the augen gneiss terrain. Figures 21 and 22 are the statistical correlation plots of the apparent resistivity data obtained at the same stations. The plots show a good linear relationship between apparent resistivity values obtained from the different arrays with coefficient of correlation $(R)$ for the Hummel/conventional Schlumberger and Half-Hummel/conventional Schlumberger arrays ranging between 0.95 and 0.99 .

As shown in Figures 23(a) and 23(b), there are similarities in the results of interpretation of the field data obtained from two different VES stations across amphibolite (locations 16 and 19). Figure 24 shows that the topsoil resistivity and thickness obtained from conventional Schlumberger and modified Schlumberger arrays were virtually the same for VES stations on amphibolite. The layer parameters obtained show some degree of correlation for the VES stations across the same lithology (Figure 25). Also, Figure 26 shows that the basement resistivity values from the different arrays are very similar for the amphibolite terrain. Figures 27 and 28 show the statistical correlation plots of the apparent resistivity data obtained at the same stations. The plots show a good linear relationship between apparent resistivity values obtained from the different arrays with coefficient of correlation $(R)$ for the Hummel/conventional Schlumberger and Half-Hummel/conventional Schlumberger arrays ranging between 0.94 and 0.99 .

Based on the 1D resistivity and depth models for the different arrays used at each location, it was observed that there is good correlation in many of the locations in terms of respective resistivity, thickness of each layer, and depth to basement (Table 1). This therefore suggests that for groundwater resources exploration, any of these arrays can be adopted to effectively characterize electrostratigraphic sections in the subsurface. The degree of correlation (statistical analysis) of the different arrays used was good in most of the locations of study which suggests that the data quality was good and subsurface models obtained from any of the arrays will be the actual representation of the subsurface configuration at such location.

Although there is relatively high values of percentage difference obtained from the test of hypothesis for the conventional Schlumberger array and modified Schlumberger 


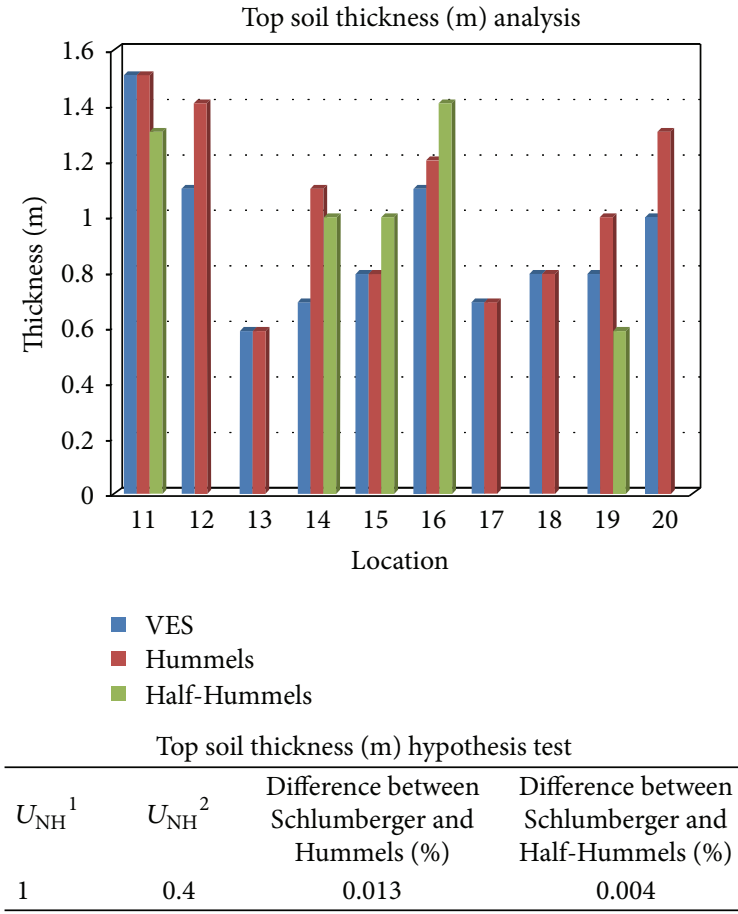

(a)

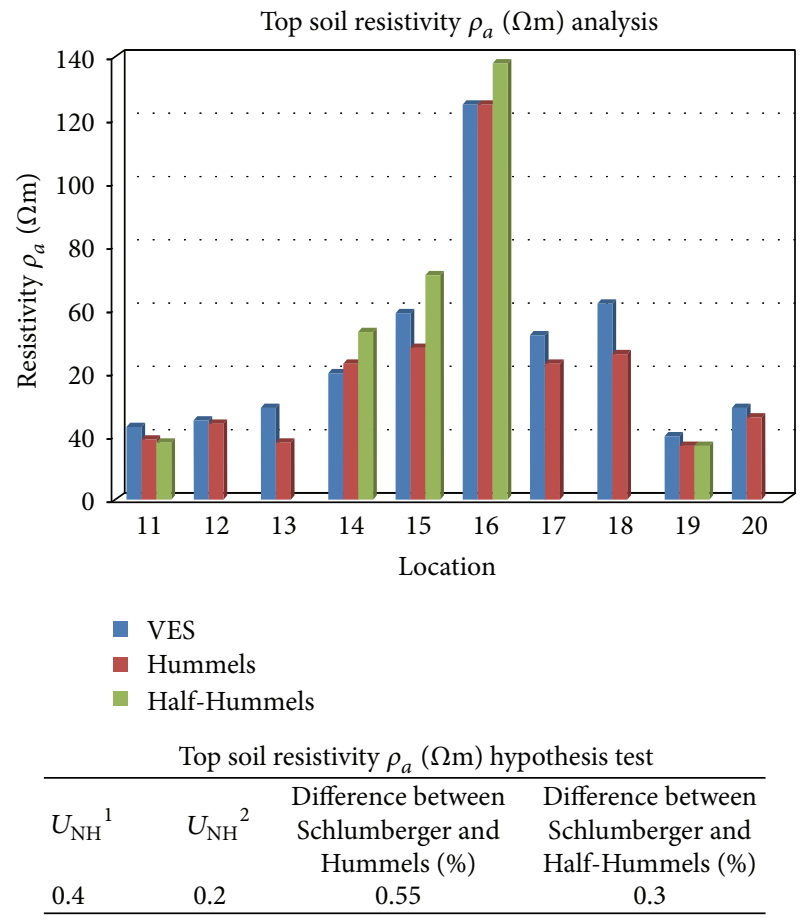

(b)

FIGURE 24: Bar chart and statistical test of hypothesis table for the different array methods comparing (a) topsoil thickness and (b) topsoil resistivity, for stations on amphibolite.

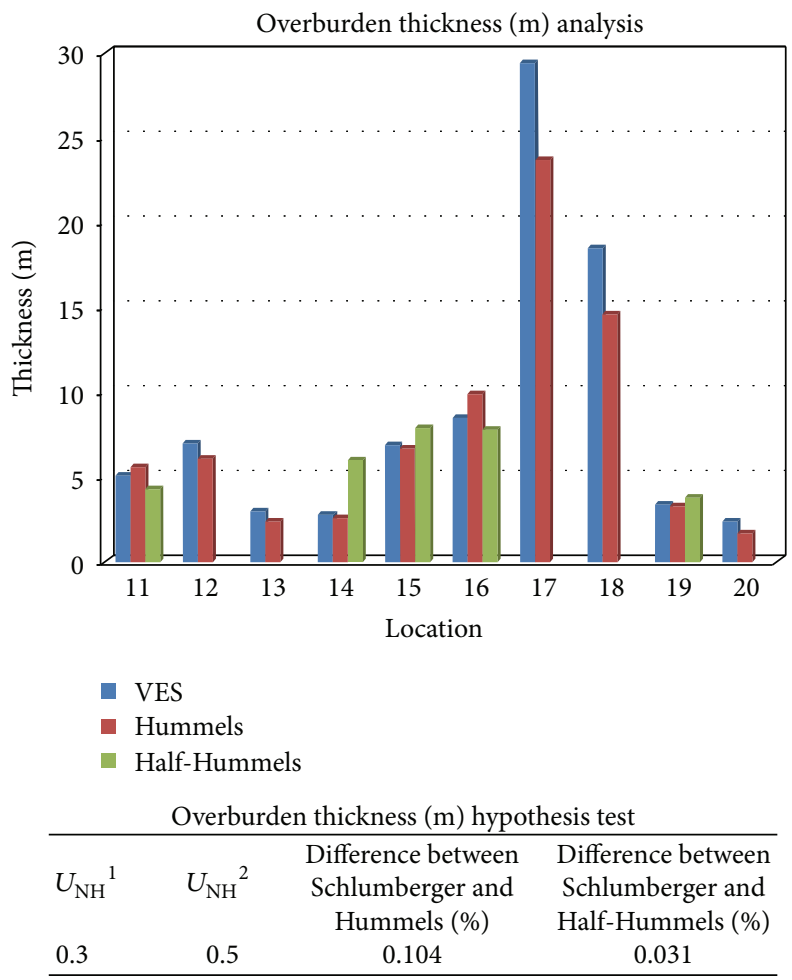

FIGURE 25: Bar chart and statistical test of hypothesis table for the different array methods comparing overburden thickness for locations on amphibolite. 


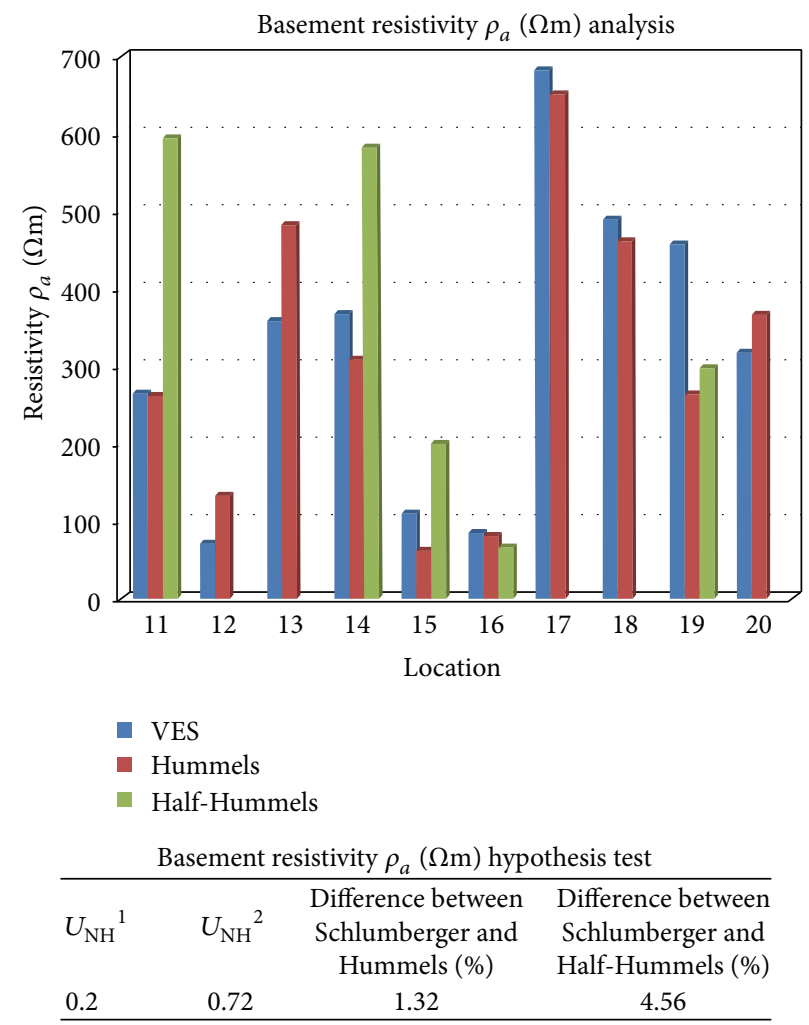

FiguRE 26: Bar chart and statistical test of hypothesis table for the different array methods comparing basement resistivity for locations on amphibolite.

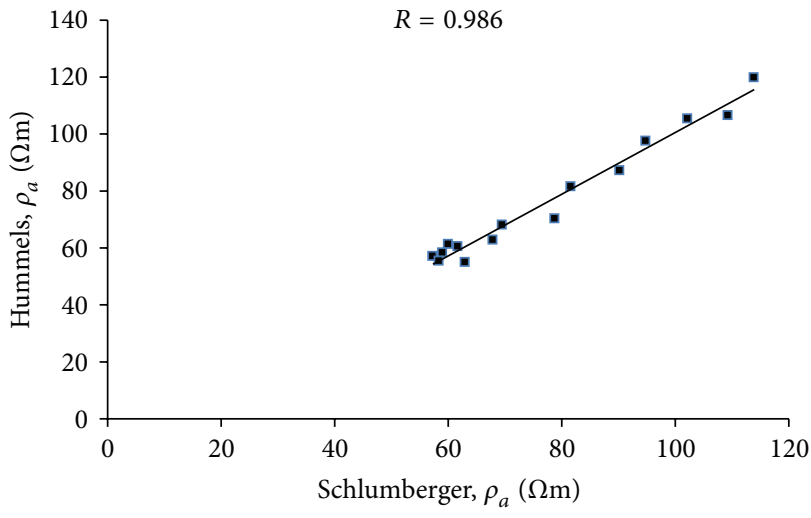

(a)

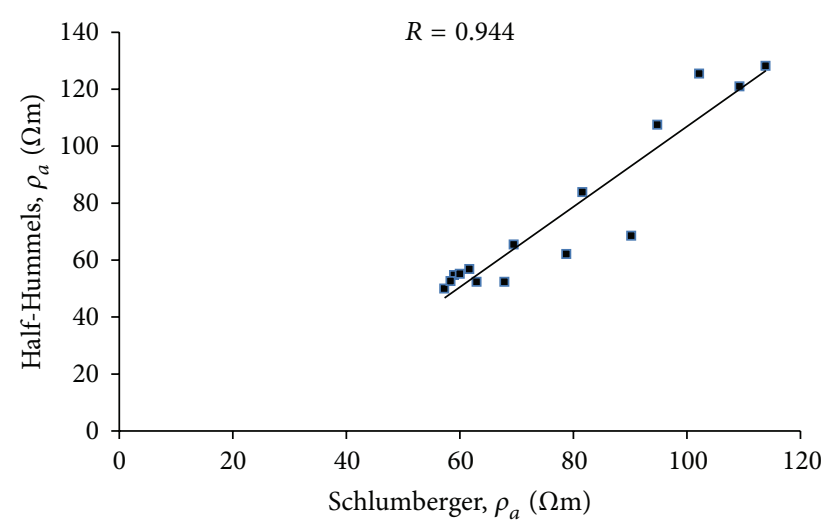

(b)

FIGURE 27: Statistical plot of apparent resistivity data for location 16 (amphibolite) (a) Hummel against conventional Schlumberger (VES) and (b) "Half-Hummel" against conventional Schlumberger (VES).

array methods across quartz schist and augen gneiss 12 (Figures 8 and 20), this has no effect on the quality of correlation between the two methods as the high value was due to high basement resistivity values obtained across these lithologies.

\section{Conclusions}

Geoelectrical survey at some locations within Ibadan metropolis underlain by Precambrian basement complex rocks has been undertaken using the conventional Schlumberger, Hummel, and "Half-Hummel" arrays at each point of investigation. The field data and curves obtained were interpreted quantitatively by curve matching technique and later subjected to computer assisted iterative interpretation. Various subsurface geologic units; topsoil, clay, weathered/fractured and fresh bedrock were identified. The results obtained from the different arrays were correlated with each other, that is, the field curves and statistical plots. The statistical plots of the apparent resistivities obtained 


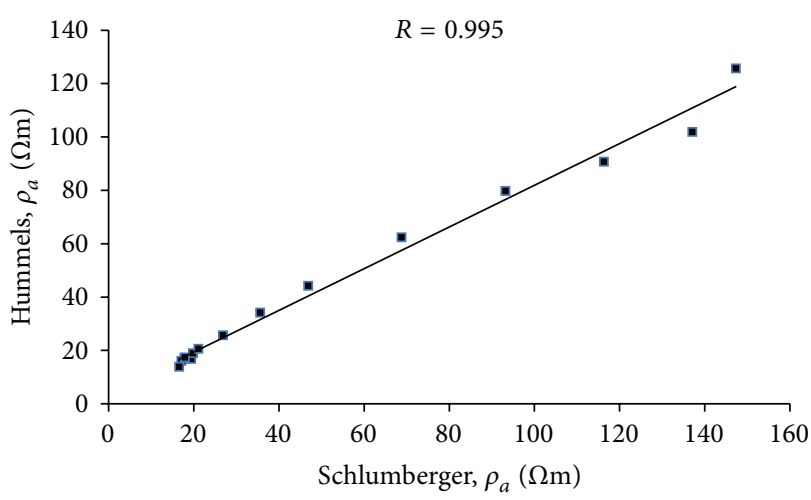

(a)

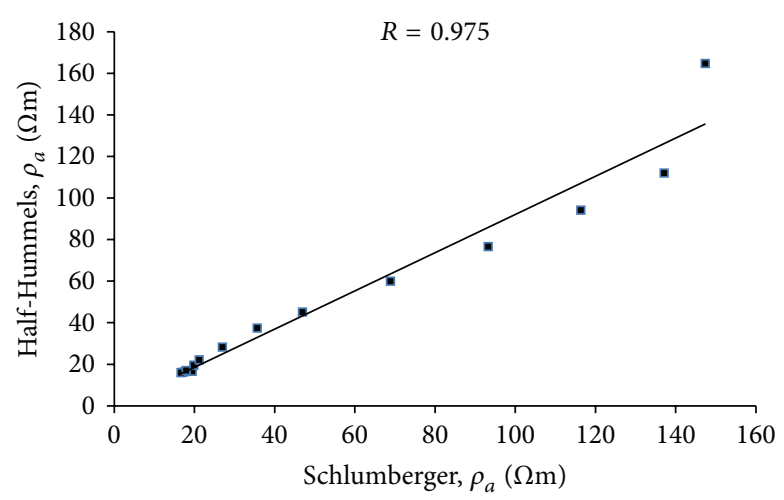

(b)

FIGURE 28: Statistical plot of apparent resistivity data for location 19 (amphibolite) (a) Hummel against conventional Schlumberger (VES) and (b) "Half-Hummel" against conventional Schlumberger (VES).

at each VES station were generated and the coefficient of correlation " $R$ " for the relationship between the different arrays was also determined.

The correlation values obtained on the different geological units indicated that the results of VES interpretation by adopting conventional Schlumberger and modified Schlumberger arrays at the same location show some degree of good correlation. This therefore implies that the modified Schlumberger array can be employed instead of the conventional Schlumberger array method in locations where there is space constraint to accommodate the symmetrical electrode configuration of the conventional Schlumberger to reasonable values of $A B / 2$ which in turn reduces the depth of investigation. In this scenario, the modified Schlumberger array utilises the little space available for its asymmetrical electrode configuration thus allowing study of subsurface to desired depth.

\section{Conflict of Interests}

The authors declare that there is no conflict of interests regarding the publication of this paper.

\section{References}

[1] M. A. Al-Garni, "Geophysical investigation for groundwater in a complex subsurface Terrain, Wadi Fatima, KSA: a case history," Jordan Journal of Civil Engineering, vol. 3, no. 2, pp. 118136, 2009.

[2] N. Shakespeare, V. Mpofu, D. Manatsa, and E. Muchuweni, "Mapping groundwater aquifers using dowsing, slingram electromagnetic survey method and vertical electrical sounding jointly in the granite rock formation: a case of matshetshe rural area in zimbabwe," Journal of Sustainable Development in Africa, vol. 12, no. 5, pp. 199-208, 2010.

[3] M. Beres Jr. and F. P. Haeni, "Application of ground-penetratingradar methods in hydrogeologic studies," Ground Water, vol. 29, no. 3, pp. 375-386, 1991.

[4] H. M. Jol and D. G. Smith, "Ground penetrating radar of northern lacustrine deltas," Canadian Journal of Earth Sciences, vol. 28, no. 12, pp. 1939-1947, 1991.
[5] D. G. Smith and H. M. Jol, "Ground-penetrating radar investigation of a Lake Bonneville deita, Provo level, Brigham City, Utah," Geology, vol. 20, no. 12, pp. 1083-1086, 1992.

[6] Z. Ziaqiang, H. Xianqi, L. Guangyin, L. Qunyi, and L. Jianhui, "Ground penetrating radar exploration for ground water and contamination," in Proceedings of the PIERS, pp. 1316-1320, Moscow, Russia, August 2009.

[7] J. de Menezes Travassos and P. de Tarso Luiz Menezes, "GPR exploration for groundwater in a crystalline rock terrain," Journal of Applied Geophysics, vol. 55, no. 3-4, pp. 239-248, 2004.

[8] J. G. Paine and E. W. Collins, "Applying airborne electromagnetic induction in groundwater salinization and resource studies, West Texas," in Proceedings of the Symposium on the Application of Geophysics to Engineering and Environmental Problems, pp. 722-738, Environmental and Engineering Geophysical Society, 2003.

[9] A. R. Alisiobi and B. D. Ako, "Groundwater investigation using combined geophysical methods," in Poster Presentation at AAPG Annual Convention and Exhibition, Long Beach, Calif, USA, April 2012.

[10] Nigeria Geological Survey Agency Bulletin, Geological Map of Ibadan, Oyo State, Nigeria, Nigeria Geological Survey Agency Bulletin, 2009.

[11] M. O. Olorunfemi and M. A. Olorunniwo, "Geoelectric parameters and aquifer characteristics of some parts of southwestern Nigeria," Geologia Applicata e Idrogeologia, vol. 20, no. 1, pp. 99109, 1985.

[12] A. R. Dodds and I. Drago, "Integrated geophysical methods used for groundwater studies in the Murray basin, South Australia," in Geotechnical and Environmental Geophysics, vol. 11, pp. 303-310, SEG Publications, 1986.

[13] A. I. Olayinka, "Electromagnetic profiling and resistivity sounding in groundwater investigation Egbada-Kabba, Kwara State," Nigerian Journal of Mining and Geology, vol. 26, no. 2, pp. 243250, 1990.

[14] M. A. Dan-Hassan and M. O. Olorunfemi, "Hydro-geophysical investigation of a basement terrain in the north-central part of Kaduna State, Nigeria," Journal of Mining and Geology, vol. 35, no. 2, pp. 189-206, 1999. 
[15] B. A. Adetola and A. O. Igbedi, "The use of study of Agbede, Southwestern Nigeria," Water Resources-Journal of the Nigerian Association of Ilydrogeologists, vol. 11, pp. 7-13, 2000.

[16] S. A. Amidu, Geoelectric imaging and geochemical method in environmental impact assessment of a septic tank in Ibadan, southwestern Nigeria [M.S. thesis], University of Ibadan, Ibadan, Nigeria, 2004.

[17] M. O. Olorunfemi, J. S. Ojo, A. I. Idornigie, and W. E. Oyetoran, "Geophysical investigation of structural failure of a factory site in Asaba area, southern Nigeria," Journal of Mining and Geology, vol. 41, no. 1, pp. 111-121, 2005.

[18] B. Nick and K. Katerina, "Application of half Schlumberger configuration for detecting karstic cavities and voids for a wind farm site in Greece," Journal of Earth Sciences and Geotechnical Engineering, vol. 1, no. 1, pp. 101-116, 2011.

[19] O. J. Akintorinwa and O. Abiola, "Comparison of schlumberger and modified schlumberger arrays VES interpretation results," Research Journal in Engineering and Applied Sciences, vol. 1, no. 3, pp. 190-196, 2012.

[20] A. I. Olayinka and G. O. Adeyemi, "Geological, geophysical and geotechnical investigations around the solehbonah quarry site near Aramed premises, kilometre 15, Ibadan Lagos dual carriage way," Tech. Rep., Department of Geology, University of Ibadan, Ibadan, Nigeria, 2001.

[21] O. O. S. Ojo and O. S. Awokola, "Determination of groundwater physiochemical parameters of shallow aquifers in agbowo and ajibode communities in Oyo State, Southwestern Nigeria," International Journal of Engineering Research and Development, vol. 3, no. 5, pp. 10-23, 2012.

[22] N. G. Obaje, "Solid mineral resources," in Geology and Mineral Resources of Nigeria, vol. 120 of Lecture Notes in Earth Sciences, pp. 117-154, Springer, Berlin, Germany, 2009.

[23] O. A. Oyinloye, "Geology and geotectonic setting of the basement complex rocks in South Western Nigeria: implications on provenance and evolution," in Earth and Environmental Sciences, I. A. Dar, Ed., chapter 5, InTech, Rijeka, Croatia, 2011.

[24] A. I. Olayinka and A. A. Oyedele, "Geoelectrical investigation of sites along the proposesd Ibadan Ilorin dual carriageway," Journal of Mining and Geology, vol. 37, no. 2, pp. 163-175, 2001.

[25] F. O. Akintola, "Geology and hydrology," in Ibadan Region, M. O. Filani, F. O. Akintola, and C. O. Ikporukpo, Eds., pp. 18-28, Rex Charks, 1994.

[26] A. B. Durotoye, "Quarternary sediments in Nigeria," in Geology of Nigeria, C. A. Kogbe, Ed., Elizabethan Press, Lagos, Nigeria, 1976.

[27] A. I. Olayinka and U. Yaramanci, "Choice of the best model in 2-D geoelectrical imaging: case study from a waste dump site," European Journal of Environmental and Engineering Geophysics, vol. 3, no. 3, pp. 221-244, 1999.

[28] A. M. MacDonald, J. Davies, and B. E. Dochartaig, "Simple methods for assessing groundwater resources in low permeability areas of Africa," British Geological Survey Commissioned Report CR/01/168N, 2002.

[29] W. M. Telford, L. P. Geldart, and R. E. Sheriff, Applied Geophysics, Cambridge University Press, 2nd edition, 1990.

[30] W. M. Telford, L. P. Geldart, R. E. Sheriff, and D. A. Keys, Applied Geophysics, Cambridge University Press, New York, NY, USA, 1978.

[31] D. S. Parasnis, Principles of Applied Geophysics, Chapman and Hall, London, UK, 5th edition, 1986.
[32] E. Orellana and H. M. Mooney, Master Tables and Curves for Vertical Electrical Sounding over Layered Structures, Interciencia, Madrid, Spain, 1966.

[33] O. Koefoed, Geosounding Principles, Electrical Resistivity Measurements, Elsevier, Oxford, UK, 1979.

[34] O. M. Nicholas, Schlumberger Vertical Soundings: Techniques and Interpretations with Examples from Krlsuvlk and Glerardalur, Iceland and Olkaria, Kenya, Geothermal Training Programme-United Nations University, 1986. 

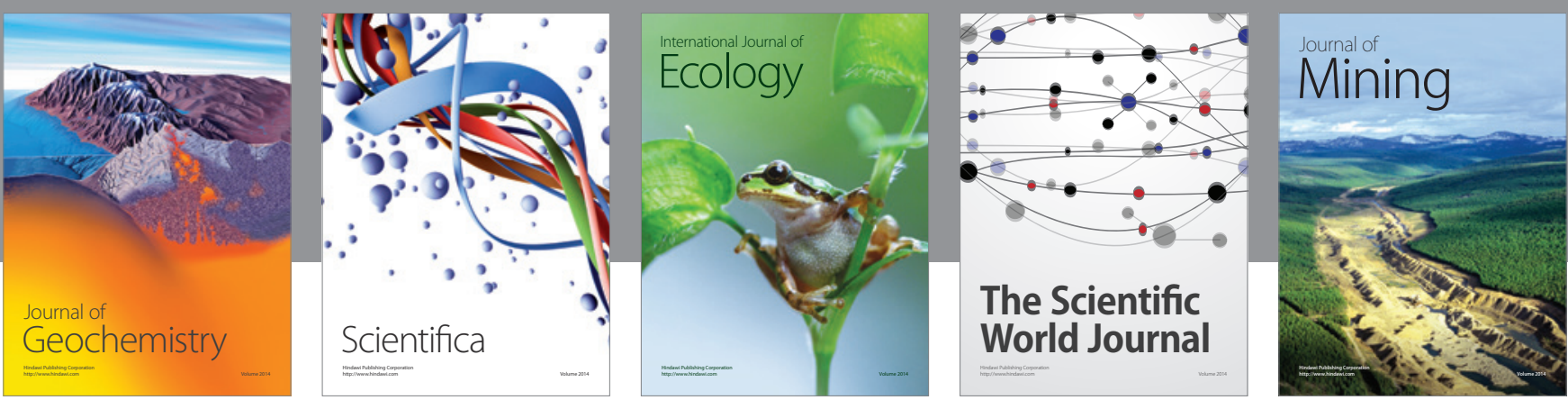

The Scientific World Journal
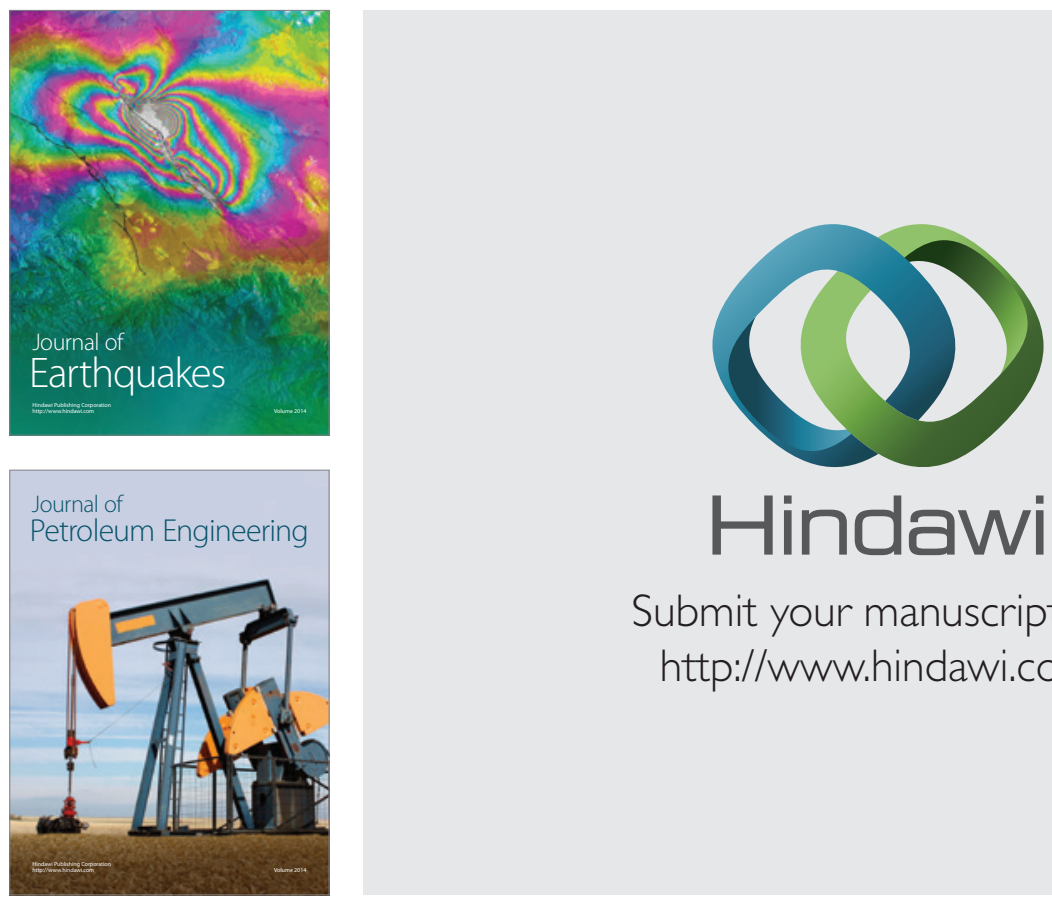

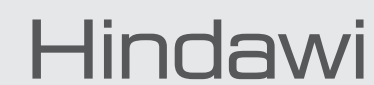

Submit your manuscripts at

http://www.hindawi.com
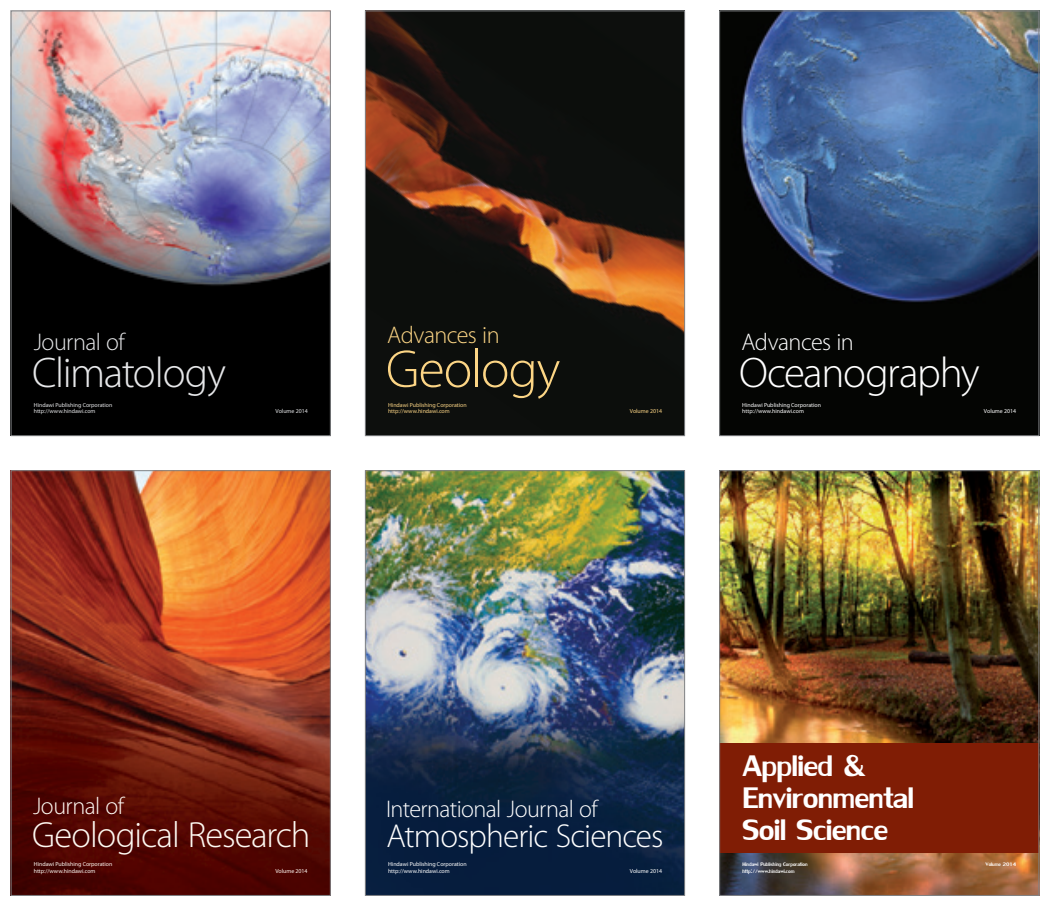
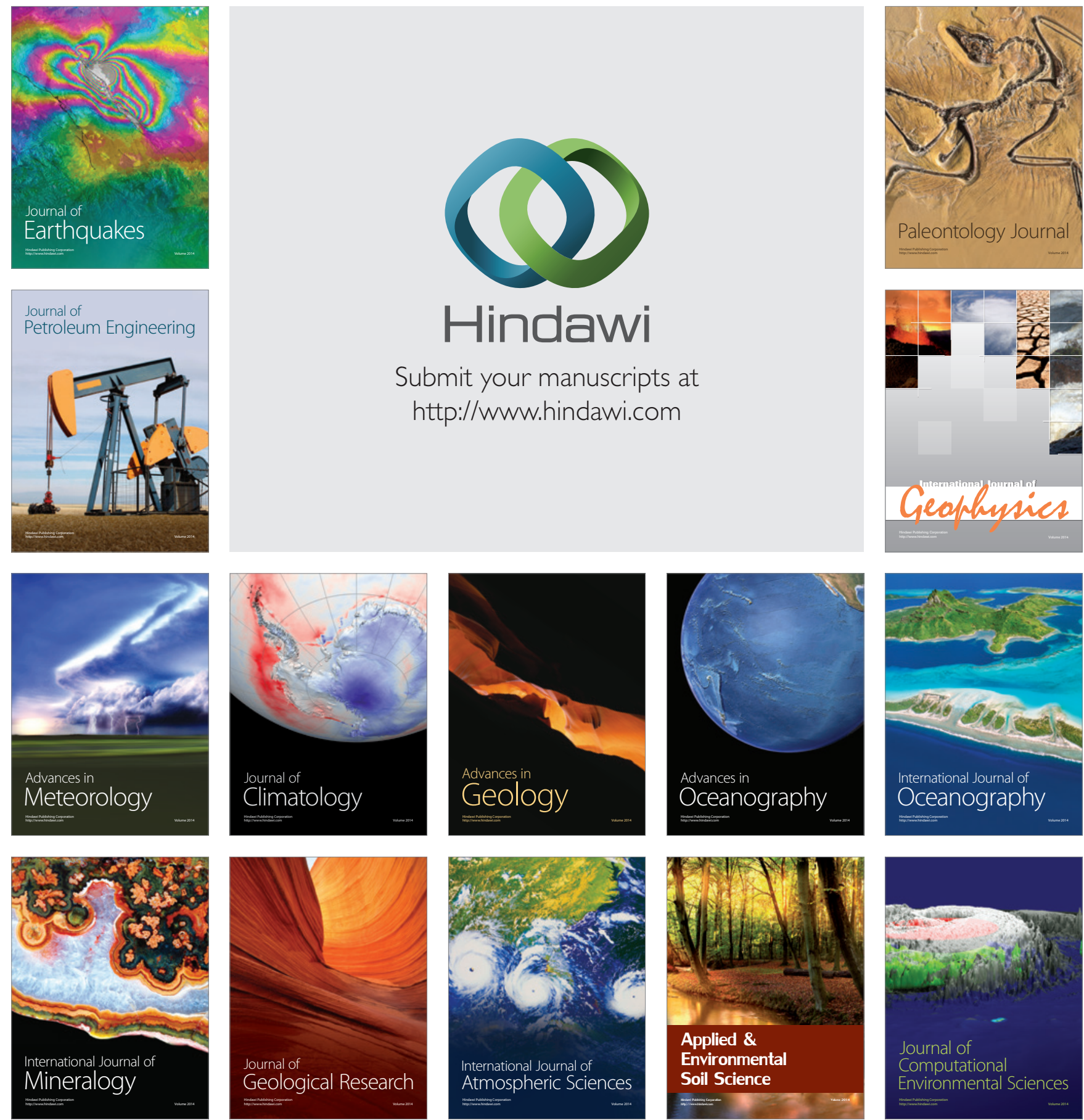